Florida International University FIU Digital Commons

5-25-2011

\title{
Work Engagement as a Mediator Between Personality and Citizenship Behavior
}

Alejandra Matamala

Florida International University, amata005@fiu.edu

DOI: $10.25148 /$ etd.FI11120613

Follow this and additional works at: https://digitalcommons.fiu.edu/etd

\section{Recommended Citation}

Matamala, Alejandra, "Work Engagement as a Mediator Between Personality and Citizenship Behavior" (2011). FIU Electronic Theses and Dissertations. 507.

https://digitalcommons.fiu.edu/etd/507

This work is brought to you for free and open access by the University Graduate School at FIU Digital Commons. It has been accepted for inclusion in FIU Electronic Theses and Dissertations by an authorized administrator of FIU Digital Commons. For more information, please contact dcc@fiu.edu. 


\title{
FLORIDA INTERNATIONAL UNIVERSITY \\ Miami, Florida
}

\section{WORK ENGAGEMENT AS A MEDIATOR BETWEEN PERSONALITY AND CITIZENSHIP BEHAVIOR}

\author{
A thesis submitted in partial fulfillment of the \\ requirements for the degree of \\ MASTER OF SCIENCE \\ in \\ PSYCHOLOGY
}

by

Alejandra C. Matamala

2011 


\section{To: Dean Kenneth Furton}

College of Arts and Sciences

This thesis, written by Alejandra C. Matamala, and entitled Work Engagement as a Mediator between Personality and Citizenship Behavior, having been approved in respect to style and intellectual content, is referred to you for judgment.

We have read this thesis and recommend that it be approved.

Chockalingam Viswesvaran

Valentina Bruk-Lee

Victoria Pace, Major Professor

Date of Defense: May 25, 2011

The thesis of Alejandra C. Matamala is approved.

\begin{tabular}{r}
\hline $\begin{array}{r}\text { Dean Kenneth Furton } \\
\text { College of Arts and Sciences }\end{array}$ \\
\hline Dean Lakshmi N. Reddi \\
University Graduate School
\end{tabular}

Florida International University, 2011 


\section{DEDICATION}

I dedicate this thesis to my mom and my sisters. I thank them for their

encouragement, love, and support, without which the completion of this work would not have been possible. 


\section{ACKNOWLEDGMENTS}

I would like to thank my committee members for their assistance, support, and advice. I would especially like to thank my major professor, Victoria Pace, whose encouragement and guidance enabled me to accomplish this study successfully. Also, I am indebted to my colleagues and friends who offered unconditional support throughout the process. Lastly, a special thanks to my cat, Symba, for keeping me company during the many late-night writing sessions. 
ABSTRACT OF THE THESIS

\title{
WORK ENGAGEMENT AS A MEDIATOR BETWEEN PERSONALITY AND CITIZENSHIP BEHAVIOR
}

\author{
by \\ Alejandra C. Matamala \\ Florida International University, 2011 \\ Miami, Florida \\ Professor Victoria Pace, Major Professor
}

This study examined individual differences as precursors to engagement, then assessed whether engagement was a mechanism through which the personality variables led to organizational outcomes. Specifically, this study assessed how the relationships between select personality dimensions and citizenship behavior (OCB), both individual (OCB-I) and organizational (OCB-O), were mediated by work engagement using two distinct measures. Undergraduate working students at Florida International University completed surveys that measured their personalities, levels of work engagement, and citizenship behaviors in the work setting. Correlations and multiple regressions were used to assess the relationships between variables. Results confirmed several of the hypotheses, including the effects of personality on engagement and engagement on OCB. Select hypotheses involving mediation were supported, of which further support was found for the UWES measure over the MBI-GS. Results from a coworker sample contribute to the literature by complementing these results linking personality, work engagement, and OCB. 


\section{TABLE OF CONTENTS}

CHAPTER

PAGE

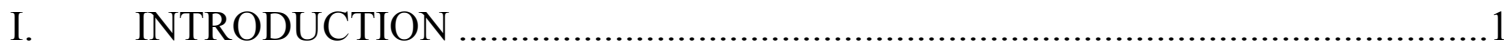

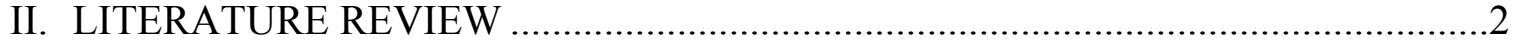

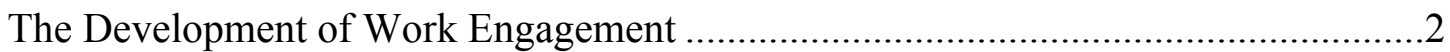

Engagement and Related Constructs ………….................................................

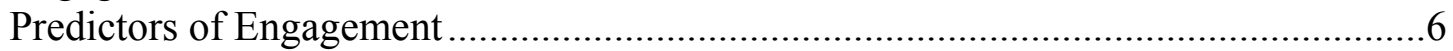

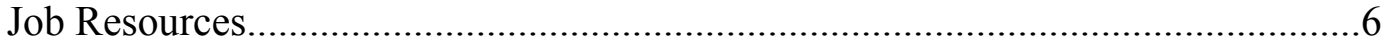

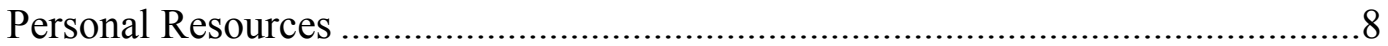

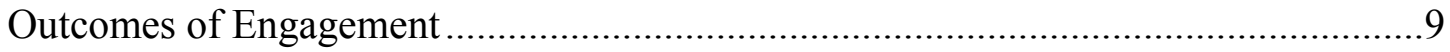

Model of Work Engagement..................................................................................

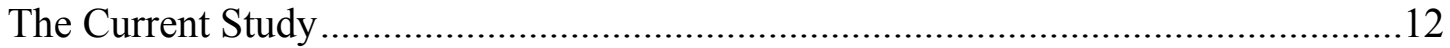

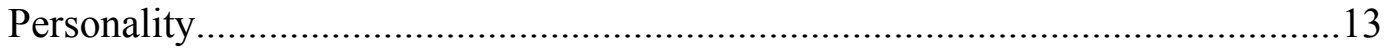

Personality and Work Engagement................................................................. 16

Organizational Citizenship Behavior (OCB) ....................................................18

Engagement and Organizational Citizenship Behavior .......................................20

Personality and Organizational Citizenship Behavior ........................................21

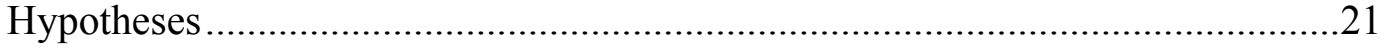

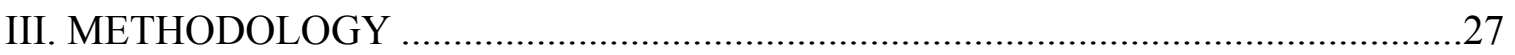

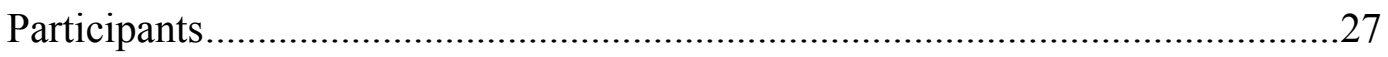

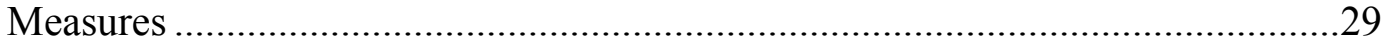

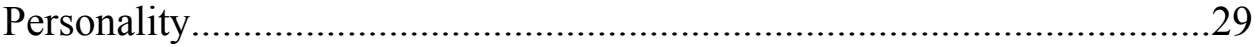

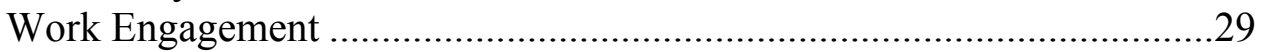

Organizational Citizenship Behavior.......................................................30

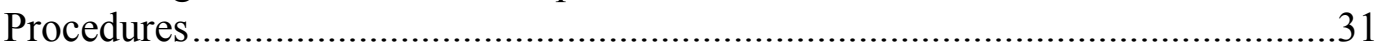

\section{RESULTS 31}

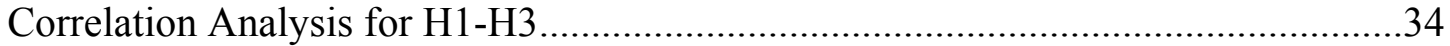

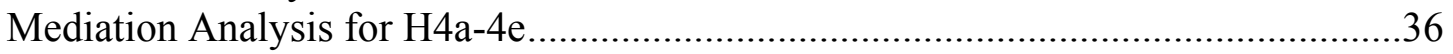

Mediation Analysis for H5 Using Distinct Work Engagement Scales ........................43

Exploratory Analysis .........................................................................................50

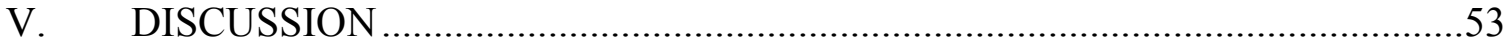

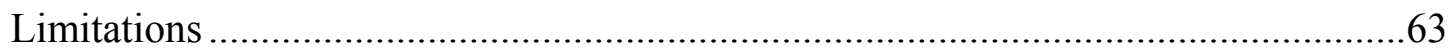

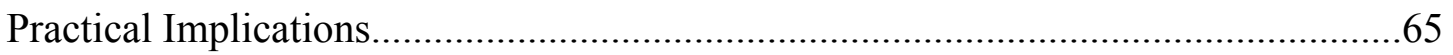

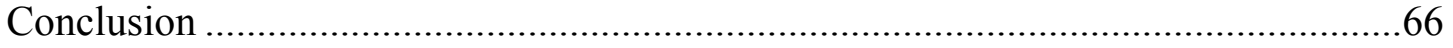

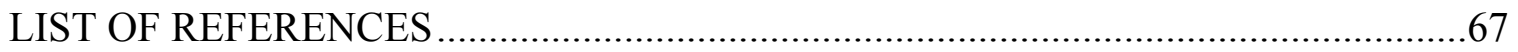

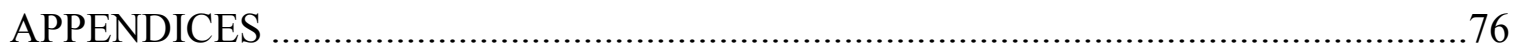




\section{LIST OF TABLES}

TABLE

PAGE

1. Means, Standard Deviations and Intercorrelations for study variables $(\mathrm{N}=499)$.......33

2. Hierarchical Multiple Regression Analysis of the Mediating Role of Engagement between Conscientiousness and OCB-O

3 Hierarchical Multiple Regression Analysis of the Mediating Role of Engagement between Agreeableness and OCB-I .

4. Hierarchical Multiple Regression Analysis of the Mediating Role of Engagement between Extraversion and OCB-I

5. Hierarchical Multiple Regression Analysis of the Mediating Role of Engagement between Neuroticism and OCB-I

6. Hierarchical Multiple Regression Analysis of the Mediating Role of Engagement between Neuroticism and OCB-O

7. Hierarchical Multiple Regression Analysis of the Mediating Role of Engagement between Conscientiousness and OCB-O with Scale Comparison

8. Zero- and First-Order Correlations between Conscientiousness and OCB-O with Scale Comparison

9. Hierarchical Multiple Regression Analysis of the Mediating Role of Engagement between Extraversion and OCB-I with Scale Comparison.

10. Zero- and First-Order Correlations between Extraversion and OCB-I with Scale Comparison. 


\section{Chapter I}

Introduction

Research on work engagement has advanced considerably in both the academic and applied arenas in the past several years; however, much is still unknown about the construct. Specifically, there is little research investigating possible predispositions to become engaged and the potential role that engagement has in the workplace. My study examines various individual differences I believe are precursors to engagement, then assess whether engagement is a mechanism through which these personality variables lead to desirable organizational outcomes. In particular, I seek to examine how the relationship between select personality dimensions and citizenship behavior (OCB), both individual (OCB-I) and organizational (OCB-O), are mediated by work engagement. Engaged employees are widely perceived as being a key ingredient for a productive workforce (Erikson, 2005). When employees are engaged, they harness themselves to their work by investing themselves physically, cognitively, and emotionally in work role performances (Kahn, 1990). Similarly, researchers have invested considerable energy examining the antecedents contributing to engagement, and consequently, the aforementioned positive organizational outcomes. Core to this research, Bakker and Demerouti’s (2004) model of work engagement outlines the process through which personal and situational resources work through engagement to impact organizations. Therefore, driven by positive organizational outcomes of engagement, and guided by the research surrounding this model, organizations are investing in interventions to increase employee engagement. 
The following section will examine the development of work engagement, followed by work engagement's nomological network as defined by Bakker and Demerouti's (2004) work engagement model, including job and personal antecedents as well as performance outcomes. Lastly, I will review the specific constructs pertaining to this study and the hypotheses to be tested. Specifically, I will discuss personality and $\mathrm{OCB}$, both independently and in terms of the proposed relationships between them and work engagement.

\section{Chapter II}

\section{Literature Review}

\section{The Development of Work Engagement}

Although there is some debate over the specific scope of work engagement, most researchers agree that it consists of high levels of energy and strong identification with one's work (Bakker, Schaufeli, Leiter, \& Taris, 2008). Schaufeli, Salanova, GonzalezRoma, and Bakker (2002) defined engagement as "a positive, fulfilling, work-related state of mind that is characterized by vigor, dedication, and absorption" (p.74).

One of the first conceptualizations of engagement was offered by Kahn (1990), who described it as “. . . harnessing of organizations members' selves to their work roles: in engagement, people employ and express themselves physically, cognitively, emotionally and mentally during role performances" (p. 694). In other words, work engagement is a dynamic, dialectical relationship between the employee's personal energies (physical, cognitive, emotional, and mental) towards the work role and the freedom (or constraints) associated with the work role for the employee to enact such energies (Kahn, 1990, 1992). The defining characteristic of this conceptualization is 
engagement as a behavior, driving energy towards one's focus on a role, versus a particular mental state as described in conceptualizations below.

Shortly after the work by Kahn (1990, 1992), Rothbard (2001) challenged the conceptualization of engagement by proposing a two-dimensional motivational construct encompassing attention and absorption. Specifically, attention was defined as "the cognitive availability and the amount of time one spends thinking about a role" (p. 56) whereas absorption was described as "the intensity of one's focus on a role" (p. 656). The key distinction between this model and Kahn's previous research, is a shift in focus from the employee's work role, to the work itself, or activity (Bakker et al., 2008).

Ironically, however, contemporary research on work engagement stems from existing research on employee burnout. Burnout, characterized by exhaustion, depersonalization or cynicism and reduced professional efficacy (Maslach, Schaufeli, \& Leiter, 2001), causes employees to view work as stressful and demanding. In 1997, Maslach and Leiter defined engagement as the opposite of burnout, such that individuals with low levels of burnout would experience high levels of engagement. Specifically, they operationalized engagement by essentially renaming the three burnout dimensions; emotional exhaustion switched to high energy, depersonalization to strong involvement, and reduced sense of efficacy to sense of efficacy. Consequently, an engaged employee would demonstrate high levels of energy and connection with their work. However, there is disagreement in the literature in terms of whether or not engagement truly is the opposite of burnout, or if it is composed of larger, more complex dimensions (Britt, Castro, \& Adler, 2005; Maslach et al., 2001; Schaufeli et al., 2002; Shirom, 2003). 
Of the researchers who disagree with the concept of engagement being on the opposite continuum as burnout, most define work engagement as ". . . a positive, fulfilling, work-related state of mind that is characterized by vigor, dedication, and absorption" (Schaufeli et al., 2002, p.74). Vigor represents high levels of energy and resilience while working, a willingness to invest effort in work, a low tendency to be fatigued, and persistence in the face of difficulties. Dedication is defined as a sense of enthusiasm, inspiration, and pride, as well as a strong involvement in work. The last of the three dimensions, absorption, is characterized by employees being happily immersed in their work, such that time passes quickly and one has difficulties detaching. As compared to burnout, vigor lies on the same "energy" continuum as would exhaustion, whereas dedication and cynicism lie on the same "identification" continuum. Thus, vigor and dedication are regarded as the core dimensions of work engagement (Schaufeli \& Bakker, 2004). Absorption was added as a third dimension of work engagement on the basis of responses from in-depth interviews (Demerouti \& Bakker, 2008). Although this three-factor model of vigor, dedication, and absorption has been confirmed using factor analysis by several researchers (Hakanen, 2002; Schaufeli et al., 2002; Schaufeli \& Bakker, 2003; Shimazu et al., 2008; Shin, 2003; Storm \& Rothmann, 2003;Yi-Wen \& YiQun, 2005), others still question the distinction of each dimension suggesting a single dimension of engagement (e.g., Hallberg \& Schaufeli, 2006; Judge, Erez, \& Bono, 1998; Wefald \& Downey, 2009).

\section{Engagement and Related Constructs}

It is also important to explain how engagement differs from seemingly similar existing constructs in the literature. Specifically, engagement is often questioned for 
being closely related to flow, satisfaction, job involvement, and job commitment (i.e., Hallberg \& Schaufeli, 2006; Wefald \& Downey, 2009). Whereas flow typically refers to "a more acute state lasting for a much shorter period and potentially of a more intense nature"(Wefald \& Downey, 2009, p. 93), engagement is described as "a more persistent and pervasive affective-cognition state that is not focused on any particular object, event, individual, or behavior" (Schaufeli et al., 2002, p. 74). Researchers also debate the amount of overlap between engagement and satisfaction. Satisfaction is commonly viewed as a measure of how happy employees are at their job (Fritzsche \& Parrish, 2005). Although the two differ conceptually, they are often highly related in terms of measurement. A possible explanation for this could be attributed to overlap in definitions, specifically, that both encompass affective reactions to the job. Consequently, some researchers endorse measuring engagement with less emphasis on the affective component (Wefald \& Downey, 2009). Similarly, job involvement and job commitment also appear to share characteristics with engagement. Job involvement is defined by Kunango (1979) as a cognitive, psychological identification with work. Commitment is defined as an emotional attachment that forms between employees and organizations on the basis of shared interests and values (Meyer \& Allen, 1997; Mowday, 1998). Like engagement, both involvement and commitment share a positive attachment to work, such that high levels are commonly related to positive work outcomes. However, unlike involvement, engagement is affected by role perceptions and appears to be related to mental and physical health (Brown, 1996). Similarly, although research on health perspectives of organizational commitment is sparse, commitment, like involvement, seems more dependent on extrinsic job characteristics, as opposed to intrinsic factors 
such as physical health (Hallberg \& Shaufeli, 2006). On inspection, Hallberg and Shaufeli (2006) found strong support for engagement as a separate and distinct construct from involvement and commitment through the use of conceptual differences as well as differing intercorrelations. Furthermore, engagement was found to have different associations with external variables, compared to involvement and commitment, specifically with health complaints, job and personal characteristics, and turnover intentions (Hallberg \& Shaufeli, 2006). Despite disagreement among researchers regarding the possible overlap with the above variables, many researchers support the notion that engagement is indeed a separate and unique concept (Brown, 1996; Hallberg \& Schaufeli, 2006; Wefald \& Downey, 2009).

\section{Predictors of Engagement}

To date, researchers have primarily focused on job and personal resources as antecedents of engagement in accordance with Bakker and Demerouti's (2008) model of engagement (See Appendix A.). The following section will provide an in-depth review of existing predictors of work engagement grouped by job resources and personal resources.

Job Resources. Repeatedly, the literature has shown positive relationships between work engagement and a variety of job resources, such as social support from colleagues and supervisors, performance feedback, skill variety, autonomy, and learning opportunities (Bakker \& Demerouti, 2008; Halbesleben, 2010; Schaufeli \& Salanova, 2007). Job resources, in this sense, are comprised of physical, social, or organizational aspects of the job that may (1) lower job demands and related physiological and psychological costs; (2) play a role in accomplishing work goals; or (3) encourage 
personal growth, learning, and development (Bakker \& Demerouti, 2007; Schauflie \& Bakker, 2004). According to researchers, job resources either stimulate employees' growth, learning, and development as an intrinsic motivational force, or are functional in achieving work goals, thus serving as extrinsic motivation (Bakker et al., 2008). Whether job resources serve to satisfy a basic need or assist in achieving work goals, both lead to positive organizational outcomes such that engagement is likely to take place (Schaufeli \& Bakker, 2004; Schaufeli \& Salanova, 2007).

The motivational role of job resources has been supported by several studies that show a positive relationship between job resources and job engagement. For example, research on four Dutch samples indicates a positive relationship between engagement and three distinct job resources: performance feedback, social support, and supervisory coaching (Schaufeli \& Bakker, 2004). In 2006, with a sample of over 2000 Finnish teachers (Hakanen, Bakker, \& Shaufeli), results showed a positive correlation between engagement and job control, information, supervisory support, innovative climate, and social climate. Similar results were produced with a sample of women managers in a Turkish bank, where engagement was positively predicted by job control, reward and recognition, and value fit (Koyuncu, Burke, \& Fiksenbaum, 2006). Furthermore, the relationship between job resources and engagement was confirmed through longitudinal research using both Finnish and Dutch working samples (Mauno, Kinnunen, \& Ruokolainen, 2007; Schaufeli, Bakker, \& Van Rhenen, 2008).

One should also note that the impact of job resources on engagement becomes more significant, or is moderated, in the presence of high job demands (Bakker \& Demerouti, 2007). In other words, when employees are faced with high levels of job 
demands (work, emotional, mental, or physical), job resources become more salient and increase in motivational potential. Using a sample of Finnish dentists, Hakanen, Bakker, and Demerouti (2005) tested the relationship between job resources and work engagement under conditions of high job demands. Specifically, variability in required professional skills and peer contacts (i.e., job resources) were expected to predict levels of engagement more strongly when employees were faced with high workloads or an unfavorable physical environment (i.e., high job demands). Hierarchical regression results showed support for a stronger relationship between job resources and engagement when job demands were high. Bakker, Hakanen, Demerouti, and Xanthopoulou (2007) also found support for this moderated relationship using a sample of teachers. They found that job resources, specifically supervisor support, innovativeness, appreciation, and organizational climate, particularly influenced work engagement when teachers were faced with high levels of student misconduct. Overall, these findings support Bakker \& Demerouti's (2007) model of work engagement, in that job resources gain motivational potential in the presence of high job demands.

Personal Resources. Personal resources have also been a major area of study as predictors of work engagement. Hobfoll, Johnson, Ennis, and Jackson (2003) define personal resources as positive self-evaluations that are linked to resiliency and refer to individuals' sense of their ability to control and impact their environment successfully. Research has shown that such positive self-evaluations predict goal-setting, motivation, performance, job and life satisfaction, career ambition, and other desirable outcomes (Judge, Van Vianen, \& De Pater, 2004). This is a result of the fact that higher levels of personal resources typically lead to higher levels of self-regard, which in turn leads to 
higher goal self-concordance (Judge, Bono, Erez, \& Locke, 2005). Ultimately, individuals with goal self-concordance are typically intrinsically motivated to pursue their goals, therefore achieving higher levels of performance (Luthans \& Youssef, 2007).

Results from several studies have supported the relationship between personal resources and work engagement. Rothman and Storm (2003) found that engaged South African police officers had an active coping style, such that they were problem-focused and were proactive about removing or rearranging possible stressors. Similarly, in a study of Dutch technicians, it was found that personal resources (self-efficacy, organizational-based self-esteem, and optimism) were related to higher levels of engagement. Specifically, engaged employees believed they were able to meet demands faced in a variety of different possible situations (Xanthopoulou, Bakker, Demerouti, \& Shaufeli, 2007). More recent studies have also found support linking personal resources, specifically self-efficacy, organizational-based self-esteem, optimism, and resilience, to work engagement (Bakker, Gierveld, \& Van Rijswijk, 2006; Xanthopoulou, Bakker, Demerouti, \& Shaufeli, 2008).

\section{Outcomes of Engagement}

Bakker \& Demerouti (2008) have also suggested links between work engagement and a number of performance related outcomes, specifically in-role performance, extrarole performance, and creativity. To explain this linkage, Bakker (2009) suggests four reasons why engaged workers perform better than their non-engaged counterparts. First, engaged employees often experience positive emotions such as happiness, joy and enthusiasm, which are believed to broaden people's "thought-action repertoire"- the range of potential actions the body and mind are prepared to take. This greater range 
allows attention to shift to new matters and encourages initiation of new behaviors (Frederickson, 2003). It is important to note, however, that the causality of this relationship has not been examined. Consequently, it is possible that employees who already experience high levels of positive emotions are then more likely to experience heightened levels of engagement. Second, engaged employees experience better psychological and physical health, which allows individuals to use their full mental and physical resources, and in turn facilitates performance (Bakker et al., 2008). Additionally, engaged employees create their own job and personal resources and are thus better equipped to meet job demands and achieve their work goals (Bakker \& Demerouti, 2007). Lastly, engaged employees transfer their engagement to others. Therefore, not only does an engaged employee tend to perform better, they are also likely to increase engagement levels of their fellow coworkers, thus increasing performance of the group as a whole (Bakker et al., 2008).

Despite the increasing popularity of work engagement in the literature, few studies have examined the relationship between engagement and job performance. Even so, the results obtained thus far are encouraging. In 2004, Bakker, Demerouti, and Verbeke found that peer ratings were higher for employees who demonstrated high levels of engagement, both for in-role and extra-role performance ratings. The Bakker at al. study showed that engaged employees not only performed their job well, but were also willing to go beyond job requirements. Researchers again found that higher levels of engagement led to higher in-role performance ratings within a Dutch sample across a broad range of occupations (Schaufeli, Taris, \& Bakker, 2006). The engagementperformance relationship was further supported within a sample of secretaries, such that 
engaged secretaries scored higher on both in-role and extra-role performance.

Performance measures included carrying out tasks beyond the job description such as organizing exhibitions and conventions, and web site maintenance, thus enabling highlyengaged secretaries to influence daily business more than secretaries with low engagement (Gierveld \& Bakker, 2005). Lastly, using a sample of Spanish restaurant personnel, Salanova, Agut, and Peiro (2005) found support for a mediated model in which work engagement fully mediated the relationship between organizational resources and employee performance. More recently, Rich, LePine, and Crawford (2010) found that engagement plays a key role in linking employee characteristics to employee performance in a study of 245 firefighters. Specifically, they found that work engagement mediates the relationship between employee characteristics (i.e., core self evaluations, value congruence, and perceived organizational support) and both task performance and citizenship behavior. This study highlights the link between employee characteristics and engagement, as well as between engagement and positive organizational outcomes.

\section{Model of Work Engagement}

In an effort to conceptualize the dynamics surrounding work engagement, Bakker and Demerouti (2008) proposed a model of work engagement (See Appendix A) which posits the mechanisms through which antecedents influence outcomes through engagement. As discussed, most research examining the antecedents of engagement has focused on work-related factors and personal resources (Bakker \& Demerouti, 2008; Saks, 2006). Among these, researchers have found moderate to strong correlations between work engagement and variables such as job characteristics, organizational and supervisor support, and organizational justice (Saks, 2006). Such findings are depicted 
by Bakker and Demerouti's (2008) model of work engagement that depicts job and personal resources as predictors of engagement. As mentioned above, job resources are defined as physical, social, or organizational aspects of the job that may impact job demands, work goals, or personal growth and development. Personal resources refer to positive self-evaluations, which are linked to an individual's sense of their ability to control and impact their environment successfully (Bakker \& Demerouti, 2007; Schauflei \& Bakker, 2004). Additionally, job demands are shown to moderate this relationship, such that the relationship between job and personal resources and engagement is strong when job demands are higher. Lastly, research supports engagement as a predictor of numerous organizational outcomes, including satisfaction, organizational commitment, turnover intentions, job performance, and organizational citizenship behaviors (OCB) (Hallberg \& Schaufeli, 2006; Saks, 2006; Schaufeli \& Bakker, 2004; Wefald \& Downey, 2009). Hence, as depicted in Bakker and Demerouti's (2008) model, work engagement predicts performance, which in turn feeds back into resources.

\section{The Current Study}

Researchers' preoccupation with job and personal resources as antecedents of work engagement has limited the examination of more stable personal antecedents, such as personality traits. Shaufeli et al. (2002) conceptualized engagement as a temporary mindset rather than a trait that is relatively stable over time. In other words, engaged employees are likely to be engaged in the work at various times throughout the day, month and year. Therefore, it seems logical that certain people may be more prone to becoming engaged in their work than others. My study aims to expand Bakker and Demerouti's (2008) model of work engagement by including individual differences (See 
Appendix B for proposed revised model). Specific predictors to be examined include conscientiousness, agreeableness, extraversion, and neuroticism. Additionally, although a number of relationships have been uncovered between personality variables and organizational criteria (e.g., job satisfaction, organizational commitment, and OCB; Barrick \& Mount, 1991; Ilies, Fulmer, Spitzmuller, \& Johnson, 2009; Kaplan, Bradley, Luchman \& Haynes, 2009; Tett, Jackson, \& Rothstein, 1991), little research exists on the linking mechanism between personality and such variables. Therefore, in accordance with Bakker \& Demerouti's work engagement model, and in response to a need for research, I examine engagement as a mediator of personality-performance linkages with OCB-I and OCB-O as potential outcomes. Background information on this topic, as well as further details on the hypotheses and corresponding study are discussed below. Personality

To examine individual differences more closely, I discuss the Big Five personality traits: Extraversion, Neuroticism, Conscientiousness, Agreeableness, and Openness to Experience. Most of the early studies that examined personality measures as predictors of job performance found relatively stable, low to moderate levels of support, depending on the specific construct introduced (Barrick \& Mount, 1991). Many of these studies, however, lacked a consistent way of classifying and measuring personality traits. In recent years, researchers have developed a widely-accepted taxonomy for organizing personality traits, known as the Big Five, which has helped shed light on the relationship between personality and job performance, both in-role and extra-role (Barrick \& Mount, 1991). 
Research leading to the Big Five factors of personality date back to the 1930s when a group of researchers scanned through dictionaries and identified a large database of trait terms that individuals use to describe one another (Allport \& Odbert, 1933). The list was then reduced to traits that were believed to remain relatively constant. The theory behind this approach is based on the Lexical Hypothesis, which states that as language develops over time, it will include words to describe important individual personality characteristics (Costa \& McCrae, 1976).

A few years later, Cattell (1947) used 140 of the terms identified above to study correlations of peer ratings. Upon completing a factor analysis, 16 factors emerged to account for the intercorrelations of the peer ratings. Later, in an attempt to replicate these findings, Fiske (1949) instead found that the 140 items loaded onto five factors. Numerous studies later, the same five personality factors continued to emerge (Borgatta, 1964; Norman, 1963). The Five-Factor Model (Costa \& McCrae, 1976) soon became widely accepted as an accurate model of human personality. Despite the model's popularity, some debate still exists over how to label the factors. On the basis of Norman's (1963) labeling, the five factors are comprised of Extraversion, or sociability; Neuroticism, or emotional stability; Conscientiousness; Agreeableness; and Openness to experience, or culture.

Extraversion, sometimes referred to as sociability, is associated with being talkative, gregarious, ambitious, enthusiastic, energetic, and active (Costa \& McCrae, 1976). Furthermore, Hogan (1986) found extraversion to be comprised of two main facets: ambition and sociability. Here, ambition refers to initiative, surgency, ambition 
and impetuousness, whereas sociability refers to being sociable, exhibitionist, and expressive.

Most researchers also agree on the characteristics of the second factor, Neuroticism. The Neuroticism factor has also been referenced as Emotional Stability, Stability, or Emotionality. Traits frequently associated with this factor include being anxious, fearful, insecure, depressed, bad-tempered, embarrassed, and worried (Costa \& McCrae, 1976). Taken together with the first factor, Extraversion, the two dimensions represent the "Big Two" (Eysenck, 1990).

The third dimension, which has generally been interpreted as Conscientiousness, is slightly more ambiguous than the previous two factors in terms of labeling and scope. In much of the education literature, it has been referred to as Will to Achieve or Will (Barrick \& Mount, 1991). Most researchers can agree that traits associated with this factor include being thorough, orderly, responsible, achievement-oriented, planful and hard-working (Costa \& McCrae, 1976).

The fourth dimension has frequently been called Agreeableness, but has also been labeled Likability or Friendliness. Traits commonly associated with this dimension include being warm, good-natured, tactful, compliant, compliant, and flexible. Additionally, researchers have also associated this dimension with being trusting, tolerant, and forgiving (Barrick \& Mount, 1991).

The last of the five dimensions has been the most challenging to classify. On the basis of Norman's labeling it is called Openness to Experience or Culture, but other researchers have referred to it as Intellect or Intelligence. Traits associated with this 
dimension include being imaginative, interested, cultured, broad-minded, enlightened, intelligent and artistically sensitive (Barrick \& Mount, 1991).

\section{Personality and Work Engagement}

A limited number of studies have examined the relationship between personality dimensions and work engagement. In an attempt to examine the impact of individual differences on work engagement, Langelaan, Bakker, Doornen, and Schaufeli (2006) conducted a study on a sample of 572 Dutch employees. Using Eysenck's Two Factor Model of personality, Neuroticism and Extraversion, they found support for their hypothesis that high levels of extraversion in combination with low levels of neuroticism are correlated to high levels of work engagement. Similarly, as Langelaan et al. (2006) found, work engagement is shown to be negatively related to neuroticism, thus offering support for neuroticism's negative relationship with engagement despite the absence of extraversion. More recently, the relationship between the Big Five personality dimensions and work engagement was assessed using a sample of quick-service restaurant employees (Kim, Shin, \& Swanger, 2009). Consistent with previous studies, results indicated a negative relationship between neuroticism and work engagement. It is important to note, however, that Kim et al. (2009) adopted the use of an 'extended engagement factor' which includes professional efficacy in addition to the three previously mentioned engagement factors: vigor, dedication, and absorption. Although the research on this relationship is still sparse, there is a significant amount of research supporting a moderately-strong positive relationship between neuroticism and burnout (Cano-García, Padilla-Muñoz, \& Carrasco-Ortiz, 2005; Lengelaan et al., 2006; Mills \& Huebner, 1998; Zellars, Hochwarter, Perrewe', Hoffman, \& Ford, 2004). Given the 
support showing engagement as having polar opposite characteristics as burnout, it seems safe to assume that the relationship with neuroticism would also be reversed. In other words, individuals high on neuroticism would be expected to display low levels of engagement.

Although less empirical research examines the effects of the other three personality dimensions, a few studies show promising results. In addition to finding support between neuroticism and engagement as mentioned above, Kim et al. (2009) also found conscientiousness to be positively related to the majority of engagement subdimensions. Moreover, by definition, conscientious workers are characterized as being organized and exacting in the work, as well as hardworking and dependable (Barrick \& Mount, 1991; Costa \& McCrea, 1988). On the other hand, engaged employees are typically found to have higher levels of performance (Hallberg \& Schaufeli, 2006; Saks, 2006; Schaufeli \& Bakker, 2004; Wefald \& Downey, 2009), which would require an employee to exhibit many conscientiousness-related traits, such as hardworking and dependable. Furthermore, upon exploratory assessment of the conscientiousnessengagement relationship, researchers have found support indicating that employees high on conscientiousness also display high levels of engagement (Dullaghan, Loo, \& Johnson, 2010; Halbesleben, Harvey, \& Bolino, 2009; Matamala, Pace, \& Thometz, 2010).

Similarly, Agreeableness refers to the tendency to be cooperative, helpful, and selfless (Digman, 1990), and has been shown to foster cooperation and teamwork (Morgeson, Reider, \& Campion, 2005). Again, engaged employees would seek efficient 
execution of their own duties, which would often require cooperation with others and selflessness towards the task at hand, particularly in the team setting.

As previously mentioned, research has linked personality and work engagement to a number of organizational outcomes. My study will examine the mechanisms through which these constructs promote organizational citizenship behavior. Specifically, my study will examine work engagement as the mechanism through which personality predicts citizenship behavior. The following section will provide an overview of citizenship behavior, both individual-targeted citizenship behavior (OCB-I) and organization-targeted citizenship behavior (OCB-O), followed by a review of personalityand engagement-related OCB findings.

\section{Organizational Citizenship Behavior (OCB)}

The term "organizational citizenship behaviors" can be dated as far back as 1964 when Katz defined it as extra-role behavior. Since then, a variety of different conceptualizations and definitions have appeared in the literature (Organ, 1988, 1990; Podsakoff, Whiting, Podsakoff, \& Blume, 2009; Williams \& Anderson, 19991). However, the two models developed by Organ $(1988,1990)$ and Williams and Anderson (1991) have emerged as the most popular conceptualizations.

Organ defined OCB as "individual behavior that is discretionary, not directly or explicitly recognized by the formal reward system, and in the aggregate promotes the efficient and effective functioning of the organization" (Organ, 1988, p. 4). The original five factor OCB model consisted of altruism, courtesy, conscientiousness, civic virtue, and sportsmanship, but was later modified to include peacekeeping and cheerleading (Organ, 1990). Alternatively, Borman and Motowidlo (1993) offered a different 
conceptualization in terms of how OCB "shapes the organizational, social and psychological context that serves as the critical catalyst for task activities and processes" (p. 71). Specifically, the model eliminates the "extra-role" emphasis proposed by Organ $(1988,1990)$ and organizes OCB on five dimensions: persisting enthusiasm to complete task, volunteering to carry out tasks outside of job description, helping others, and supporting organizational objectives (Borman, Penner, Allen, \& Motowidlo, 2001).

Williams and Anderson (1991) later proposed a similar, but distinct conceptualization of OCB that is derived from the direction of the behavior. Specifically, OCB-I denotes behaviors directed toward the benefit of other individuals, such as helping others who have been absent or helping others who have heavy workloads. On the other hand, OCB-O denotes behaviors directed toward the benefit of the organization such as giving advance notice when unable to come to work or adhering to informal rules devised to maintain order. Notably, all of Organ's dimensions are captured in William and Anderson's conceptualization. Furthermore, other OCB-related constructs such as interpersonal helping, interpersonal facilitation, helping coworkers and interpersonal harmony are also incorporated in the OCB-I scheme. Similarly, the OCB-O scheme encompasses organizational loyalty, endorsing, supporting and defending organizational objectives, job dedication, voice behavior, taking charge, and promoting a company's image (Podsakoff et al., 2009).

Despite the variance in defining the framework of the construct, the practical importance of OCB in the workplace is clear. According to Organ (1988), OCB improves organizational effectiveness and efficiency by contributing to resource transformations, innovativeness, and adaptability. Furthermore, findings from a recent 
meta-analysis by Podsakoff et al. (2009) indicate that OCB is related to several individual-level and organizational-level outcomes. Specific individual-level outcomes include managerial ratings or employee performance, reward allocation decisions, and a variety of withdrawal-related criteria. Relationships with specific organizational-level outcomes include productivity, efficiency, reduced costs, customer satisfaction, and unitlevel turnover.

Engagement and Organizational Citizenship Behavior

Given the recent introduction of work engagement as a research field, few researchers have had the opportunity to explore the effects of engagement on specific OCBs. However, as previously discussed, there is some exploratory research on performance that examines both in-role performance and extra-role performance, which is highly related to OCB. Recently, Abcock-Robertson and Strickland (2010) examined the relationship between leadership, work engagement, and citizenship behavior using a sample of working adults. Results showed support for a strong positive relationship between work engagement and OCB. Furthermore, their findings suggested work engagement fully mediated the linkage between charismatic leadership characteristics and OCB. As mentioned earlier, Rich et. al. (2010) also found that work engagement was not only positively related to citizenship behaviors, but that it also mediated the relationship between personal characteristics and OCB. Similarly, exploratory analysis of antecedents and consequences of work engagement further confirmed a positive relationship between engagement and citizenship behavior (Matamala et al., 2010; Dullaghan et al., 2010). 


\section{Personality and Organizational Citizenship Behavior}

According to Motowidlo, Borman and Schmit (1997), contextually oriented behaviors are more strongly influenced by personality than by cognitive ability. In agreement with this view, considerable research has surfaced examining the personalityOCB relationship (Borman et al., 2001; Dalal, 2005; Hurtz \& Donovan, 2000; Moon, Hollenbeck, Marinova, \& Humphrey, 2008; Organ \& Ryan, 1995; Podsakoff, MacKenzie, Paine, \& Bachrach, 2000). Of the Big Five personality traits, three have been found to predict OCB: conscientiousness, agreeableness, and extraversion (Moon et al., 2008; Organ \& Ryan, 1994, 1995; Organ \& Lingl, 1995).

However, a significant body of literature suggests OCB-related research should distinguish between OCB dimensions, specifically individual-targeted and organizationtargeted (OCB-I and OCB-O). A recent meta-analysis by Dalal (2005) found support for OCB-I and OCB-O as distinct dimensions of OCB. Further evidence for distinctiveness was offered by Ilies, Nahrgang, \& Morgeson (2007) in a study on the effects of leadermember exchange (LMX), in which an interpersonal exchange variable was more strongly associated with OCB-I than OCB-O. More importantly, a recent study examining the mediating role of job satisfaction on personality and citizenship behavior found support for employing targeted citizenship behavior dimensions (Ilies et al., 2009). Specifically, the study provided support for job satisfaction as a mediator between agreeableness and OCB-I and conscientiousness and OCB-O.

\section{Hypotheses}

On the basis of the limitations in the studies discussed, this study seeks to bridge the gaps in the existing literature between personality, work engagement, and OCB. 
Specifically, my study examines personality dimensions as antecedents to work engagement, citizenship behavior as an outcome of work engagement, and work engagement as a mediator of the personality-citizenship behavior relationship. Additionally, the proposed relationships will further expand the existing work engagement model as proposed by Bakker and Demerouti (2008) by including personality dimensions as predictors of engagement.

Given the abundance of support for this topic and its prevalence in the literature, my study examines work engagement as a specific, operationalized, psychological state characterized by vigor, dedication, and absorption (Schaufeli et al., 2002). This conceptualization has been endorsed by multiple researchers through advancing research, refined test measurement, and the use of the associated Utrech Work Engagement Scale (Bakker et al., 2008). Although Schaufeli et al. (2002) found support for a three-factor model, other researchers argue for a one factor structure (Hallberg \& Schaufeli, 2006). As a result of a lack of agreement in the literature, I adopt the single-factor model as endorsed by Baker et al. (2008), but examine the three-factor model through exploratory analyses.

Although few studies have examined the relationship between personality dimensions and work engagement, preliminary findings indicate important relationships (i.e., Dullaghan et al., 2010; Kim et al. (2009) ; Langelaan et al., 2006; Matamala at al., 2010). In line with current findings, I propose significant relationships between work engagement and the following personality dimensions: conscientiousness, agreeableness, extraversion, and neuroticism. Given frequent inconsistent conceptualizations and findings of openness to experience, this dimension is not examined in this study. 
Therefore, a primary goal of this study is to further explore these relationships using the five factor model of personality, with the expectations that:

Hypothesis 1a. Conscientiousness is positively related to work engagement.

Hypothesis 1b. Agreeableness is positively related to work engagement.

Hypothesis 1c. Extraversion is positively related to work engagement.

Hypothesis 1 . Neuroticism is negatively related to work engagement.

Although existing studies show preliminary support for Bakker and Demerouti's (2008) work engagement model, it is clear that additional support is needed in order to fully understand the mechanisms through which engagement leads to positive organizational outcomes. In order to address this research gap, this study examines citizenship behavior and its relationship to both work engagement and personality dimensions. Using William and Anderson's (1991) conceptualization of OCB, this study examines citizenship behavior as an outcome of work engagement, positing that:

Hypothesis $2 a$. Work engagement is positively related to OCB-I.

Hypothesis $2 b$. Work engagement is positively related to OCB-O.

In order to fully understand the role of work engagement and $\mathrm{OCB}$, it is also necessary to examine the linkage in the context of the proposed revised work engagement model.

As results from Ilies et al. (2009) show, conscientious employees, who are characterized by strong work ethic, organization skills, and detail-oriented skills have a tendency to display more organization-targeted citizenship behavior. Alternatively, employees high on agreeableness, who typically thrive in a group setting due to high levels of flexibility and helpfulness, would naturally be more likely to display individual-targeted citizenship behavior. Additionally, although there is no empirical research, extraverted employees 
are talkative, gregarious and active, which could easily lead to high levels of individualtargeted citizenship behavior. Lastly, research indicates no reason to believe that neuroticism would differentially predict individual- and organization-targeted citizenship behavior. However, consistent with previous literature linking neuroticism to extra-role behavior, I predict individuals low on this dimension will exhibit higher levels of OCB in general. Therefore, this study further explores these relationships, such that:

Hypothesis $3 a$. Conscientiousness is positively related to OCB-O.

Hypothesis 3b. Agreeableness is positively related to OCB-I.

Hypothesis 3c. Extraversion is positively related to OCB-I.

Hypothesis $3 d$. Neuroticism is negatively related to OCB-I.

Hypothesis 3e. Neuroticism is negatively related to OCB-O.

As discussed, most previous research on the personality-OCB relationship has centered on meta-analytic techniques and has offered very little insight into why this relationship may exist. Specifically, none of these studies examined the link between personality and citizenship behavior, while also examining the role of work engagement as a possible mediator. In an attempt to build a more comprehensive model of this linkage, this study aims to extend the current literature by examining the following hypotheses:

Hypothesis 4a. Work engagement mediates the relationship between Conscientiousness and OCB-O. (See Appendix C graphical representation)

Hypothesis $4 b$. Work engagement mediates the relationship between Agreeableness and OCB-I. 
Hypothesis 4c. Work engagement mediates the relationship between Extraversion and $O C B-I$.

Hypothesis $4 d$. Work engagement mediates the negative relationship between Neuroticism and $O C B-I$.

Hypothesis 4e. Work engagement mediates the negative relationship between Neuroticism and $O C B-O$.

The above hypotheses will not only help to better understand the personalitycitizenship behavior relationship, they will help to build a more comprehensive model of antecedents and consequences of work engagement. To further strengthen and support the revised work engagement model, this study examines all proposed relationships using a second measure of work engagement. As previously mentioned, the most commonly accepted conceptualization of engagement consists of three dimensions, characterized by vigor, dedication, and absorption (Britt, et al., 2005; Maslach, et al., 2001; Schaufeli, et al., 2002; Shirom, 2003). Therefore, our first set of analyses employed the Utrech Work Engagement Scale (Bakker et al., 2008) which reflects the previously mentioned conceptualization of engagement.

However, other researchers believe engagement lies on the same, but opposite, continuum of burnout, such that individuals with low levels of burnout would experience high levels of engagement (Maslach \& Leiter, 2001). Specifically, they operationalize engagement as the opposite of the three burnout dimensions: emotional exhaustion switched to high energy, depersonalization to strong involvement, and reduced sense of self to self of efficacy. Both conceptualizations of engagement overlap on two of the three dimensions. Specifically, vigor lies on the same "energy" continuum as would high 
energy, whereas dedication lies on the same "identification" continuum as involvement. Thus, the research unanimously agrees that vigor, or high energy, and dedication, or involvement, are regarded as the core dimensions of work engagement (Schaufeli \& Bakker, 2004). However, researchers have slightly different ideas regarding the third dimension of engagement, such that Schaufeli and Bakker (2004) describe it as absorption, whereas Maslach and Leighter express it as self-efficacy. Self-efficacy, by definition, refers to a belief that one is capable of performing in a certain manner or attaining certain goals. However, self-efficacy does not involve specific actions, but rather a belief, or attitude, that may or may not influence future behavior. Absorption refers to behavior-specific ways of conducting work, which may or may not be fueled by high levels of self-efficacy. Thus, although self-efficacy may be a primary attitude predicting absorption, and thus possibly engagement, absorption is the more proximal means through which such attitudes lead to worker engagement.

Given this, it should be expected that a measure using Bakker et al.'s (2008) conceptualization of engagement would yield a stronger relationship when compared to Maslach and Leiter's (2001) measure of engagement. Consequently, a final second goal of this study is to examine further all of the above proposed relationships using two distinct measures of work engagement, such that:

Hypothesis 5. The Utrecht Work Engagement Scale, as compared to the Maslach Burnout Inventory-General Survey, more fully mediates all previously hypothesized relationships involving work engagement. 


\section{Chapter III}

Methodology

\section{Participants}

To test these hypotheses, data from a sample of students were collected from Florida International University. All participants were required to be enrolled in at least one undergraduate or graduate course and be employed at least part-time (20 hours or more per week). Additionally, each student participant had the option of asking one of their coworkers to complete a short survey online.

In order to screen the data for random responses, five test items were included in the surveys, three in the employee survey and two in the coworker survey. The test items asked participants to choose a specific answer for that item. For example, one of the test items was "Please select the response option 'Once a week'.". If an individual got the item wrong, it was presumed that the employee was not paying attention to the statement. Employees and/or coworkers that answered any of the test items incorrectly were excluded from the analyses. After performing this screening for random responses, a sample size of 499 was achieved. Of the 499 employee responses, 332 could be matched with corresponding coworker data. However, in order to ensure that employee data were authentic and not simply filled in by the target employee, a variety of methods were used to ensure good data. These included examination of: date of survey completion, time stamp of employee survey completion, time stamp of coworker survey initiation, and coworker contact information provided by employee. After performing this screening for authentic coworker responses, a coworker sample size of 114 was achieved. 
Fewer coworkers completed the survey than target employees, therefore any analyses involving coworker-reported data were run using the smaller sample. The means observed for study variables in this smaller dataset did not differ significantly from those in the larger dataset. All other analyses were run using the full dataset $(\mathrm{N}=$ 499) which consisted of self-report personality dimensions, work engagement (UWES \& MBI-GS), and citizenship behavior. The smaller dataset $(\mathrm{N}=114)$ included both the employees' reports on these variables as well as their coworkers' assessment of their citizenship behavior.

In the full dataset $(\mathrm{N}=499), 69.9 \%$ of the participants were women. Hispanics comprised a large portion of the sample (73.3\%), while $12.6 \%$ were White (nonHispanic), 7\% Black (non-Hispanic), 3.4\% Asian or Pacific Islander, 1.9\% Middle Eastern, and $1.8 \%$ described themselves as "Other." A majority of this sample (85.2\%) was $18-25$ years old, $6.8 \%$ were $26-30$ years old, $5.2 \%$ were $31-45$ years old, and $2.8 \%$ were over 45 years old. Additionally, $81.5 \%$ of the students were employed between 20 and 40 hours, while the others $(17.8 \%)$ worked 40 hours or more per week. The average tenure for the sample was 2.3 years $(S D=2.8)$. Lastly, most employees in this sample (37.7\%) worked in retail or sales, while others worked in services (23.2\%), education (12.2\%), health care (8.4\%), finance or real estate (7\%), public administration or government (5.2\%), and other $(6.2 \%)$. The smaller dataset $(\mathrm{N}=114)$ was similar to the larger dataset in that a majority of the sample fell into the following groups: females, Hispanics, employed 20 to 40 hours per week, average tenure of 2.2 years, and employed in retail or sales. 


\section{Measures}

Personality. Personality was measured with the Five Factor Model Questionnaire (FFMQ) (Gill \& Hodgkinson, 2007) which consists of 80 adjectives to assess the five major dimensions in the work setting. Participants answered using a 5-point scale to assess how well each word described the way they usually behave while at work. Response options ranged from 1 (Not like me at work) to 5 (Very like me at work). The coefficient alpha reliabilities for this study ranged from $\alpha=.72$ to $\alpha=.88$ (Agreeableness $\alpha=.88$, Conscientiousness $\alpha=.80$, Extraversion $\alpha=.79$, Neuroticism $\alpha=.76$, Openness $\alpha=.72)$.

Work Engagement. Work engagement was measured with the Utrecht Work Engagement Scale (UWES; Shaufeli et al., 2002) as well as the Maslach Burnout Inventory-General Survey (MBI-GS; Maslach, et al., 1996). The UWES is composed of three subscales that correspond to the three dimensions of engagement and can also be used to measure overall work engagement. There were six items for Vigor (e.g., "At work, I feel full of energy"; $\alpha=.76$ ). There were five items for Dedication (e.g., "I am enthusiastic about my job"; $\alpha=.85$ ). Lastly, there were six items for Absorption (e.g., "When I am working, I forget everything else around me"; $\alpha=.80)$. All of the items were scored on a 7-point Likert scale ranging from 0 (never) to 6 (every day). The coefficient alpha for overall work engagement was $\alpha=.92$.

For the Maslach Burnout Inventory-General Survey ${ }^{1}$ (MBI-GS; Maslach, Jackson \& Leiter, 1996), the subscale Exhaustion included five items $(\alpha=.90)$ the subscale

\footnotetext{
${ }^{1}$ Adapted and/or translated with permission of the Publisher, CPP, Inc. from MBI-GS. Copyright 1996, 2010 by CPP, Inc. All rights reserved. Further reproduction is prohibited without CPP's written consent.
} 
Cynicism included four items $(\alpha=.82)$, and the subscale Efficacy included six items $(\alpha=$ .79). Reproduction of specific items in this report is strictly prohibited by the test publisher. Items are scored on a 7-point Likert scale ranging from 0 (never) to 6 (every day). Cynicism and exhaustion subscales were reverse coded to compute the overall work engagement score. Several studies have shown that the MBI-GS has excellent psychometric properties, including high reliabilities of the subscales, factorial validity (e.g., Bakker, Demerouti, \& Schaufeli, 2002; Schutte, Toppinnen, Kalimo, \& Schaufeli, 2000), and construct validity (Taris, Schreurs, \& Schaufeli, 1999). The coefficient alpha for overall work engagement was $\alpha=.86$.

Organizational Citizenship Behavior. Citizenship behavior was measured using the Organizational Citizenship Behavior Checklist (OCB-C), a 29-item instrument developed by Fox and Spector (2009). The checklist is designed to assess the frequency of organizational citizenship behaviors performed by employees and is composed of two subscales, OCB-O and OCB-P. Note that OCB-P, or OCB-Person, is designed to measure what has been referred to as OCB-I in this study. Acts directed toward the organization that benefit the organization (OCB-O) were measured using 15 items, and acts directed toward coworkers that help with work-related issues (OCB-P) were measured using the remaining 14 items. A slightly modified OCB-C scale was administered to coworkers in order to gather both self-reported data and coworker data. The coefficient alphas for this study were .91 for the overall scale, .92 for OCB-O and .85 for OCB-I. Similarly, the coefficient alpha reliabilities for coworker reports were .95, .92 , and .90 , for overall, OCB-O, and OCB-I, respectively. 


\section{Procedures}

Participants were encouraged to join the study through the university's psychology research website and were informed of the study criteria prior to accessing the survey. Participants were asked to review and indicate understanding of a consent form before gaining access to the actual study. The online survey was separated into two distinct phases, with phases one and two lasting 45 and 30 minutes, respectively. Phase one included self-report measures for personality, employee engagement, and OCB. In phase two, participants were given the option of contacting a coworker to have them complete an OCB measure online pertaining to the main study participant. Participants received research participation points through the psychology department's research study management system. Each participant received 1 point (redeemable for extra credit) for successfully completing phase one, and received an additional point if phase two was successfully completed. In order to link the two surveys, employees were asked to enter a code word. They then provided this code word for their coworker to enter at the beginning of the survey for phase two. Employees and coworkers remained anonymous throughout the study.

\section{Chapter IV}

\section{Results}

Once the data were collected, preliminary analyses were conducted to ensure no violation of the assumptions of normality, linearity, multicolinearity and homeoscedasticity were present. Specifically, normality and linearity were assessed by obtaining skewness and kurtosis values, comparing trimmed versus original means, performing a test of normality using the Kolmogorov-Smirnov statistic, as well as 
examining histograms, Normal Q-Q Plots, Detrended Normal Q-Q Plots, and boxplots. For variables included in regression analyses, correlation analysis and colinearity diagnostics were used to check for multicolinearity in order to verify that independent variables were not too highly correlated. Similarly, for these relationships, assessment of homeoscedasticity was performed to ensure that the variance of the residuals about the predicted dependent variable scores was the same.

Following this step, analyses were performed to test the hypotheses. These included an analysis of correlations between variables to test hypotheses 1a $-3 \mathrm{~d}$, multiple regression analyses to test the mediating role of work engagement in specified relationships between personality dimensions and $\mathrm{OCB}$, and lastly multiple regression analyses to test mediation using two distinct measures of work engagement.

Means, standard deviations, and intercorrelations among study variables are provided in Table 1. Results from coworker and self-report data are presented for organizational citizenship behavior. Overall, there was strong convergence between self and coworker reports for OCB-I $(r=.43)$ and OCB-O $(r=.45)$. All other data are selfreported: conscientiousness, agreeableness, extraversion, neuroticism, and work engagement (Utrecht scale \& MBI-GS scale). Pearson correlation coefficients were computed to examine relationships between personality dimensions (conscientiousness, agreeableness, extraversion, neuroticism), both measures of work engagement, and OCBI and $-\mathrm{O}$. 
Table 1. Means, Standard Deviations and Intercorrelations for study variables $(\mathrm{N}=499)$

\begin{tabular}{|c|c|c|c|c|c|c|c|c|c|c|c|c|c|c|c|c|}
\hline & Variable & M & SD & 1 & 2 & 3 & 4 & 5 & $5 a$ & $5 b$ & $5 c$ & 6 & 7 & 8 & 9 & 10 \\
\hline 1. & Conscientiousness & 4.02 & .44 & .80 & $\begin{array}{ll}-- \\
--\end{array}$ & --- & $\begin{array}{ll}-- \\
--\end{array}$ & $\begin{array}{ll}-- \\
--\end{array}$ & --- & --- & --- & --- & --- & --- & --- & --- \\
\hline 2. & Agreeableness & 4.30 & .47 & $.43^{* *}$ & .88 & --- & --- & --- & --- & --- & --- & --- & --- & --- & --- & --- \\
\hline 3. & Extraversion & 3.65 & .48 & $.29 * *$ & $.32 * *$ & .79 & --- & --- & --- & --- & --- & --- & --- & --- & --- & --- \\
\hline 4. & Neuroticism & 2.41 & .52 & $-.31 * *$ & $-.43 * *$ & $-.20 * *$ & .76 & --- & --- & --- & --- & --- & --- & --- & --- & --- \\
\hline 5. & Engagement- Utrecht & 4.11 & .91 & $.27 * *$ & $.37 * *$ & $.24 * *$ & $-.19 * *$ & .92 & --- & --- & --- & --- & --- & --- & --- & --- \\
\hline & 5a. Vigor & 4.55 & .93 & $.38 * *$ & $.39 * *$ & $.33 * *$ & $-.30 * *$ & $.86^{* *}$ & .76 & --- & --- & --- & --- & --- & --- & --- \\
\hline & 5b. Dedication & 4.44 & 1.24 & $.22 * *$ & $.34 * *$ & $.21 * *$ & $-.21 * *$ & $.92 * *$ & $.71 * *$ & .85 & --- & --- & --- & --- & --- & --- \\
\hline & 5c. Absorption & 4.07 & 1.09 & $.16^{* *}$ & $.30 * *$ & $.16^{* *}$ & -.07 & $.92 * *$ & $.69^{* *}$ & $.78 * *$ & .80 & --- & --- & --- & --- & --- \\
\hline 7. & OCB-I (Coworker) & 2.59 & .74 & .12 & $.23 *$ & .05 & -.01 & .08 & .18 & .79 & .04 & .04 & .90 & --- & --- & --- \\
\hline 8. & OCB-I (Self-Report) & 2.37 & .66 & .05 & $.23 * *$ & $.16^{* *}$ & $.10^{*}$ & $.15^{* *}$ & $.17 * *$ & $.10 *$ & $.15 * *$ & .01 & $.43 * *$ & .87 & --- & --- \\
\hline 9. & OCB-O (Coworker) & 2.75 & .88 & .14 & $.22 *$ & .15 & -.06 & .18 & $.33 * *$ & .17 & .11 & .18 & $.75^{* *}$ & $.39 * *$ & .92 & --- \\
\hline 10 . & OCB-O (Self-report) & 2.54 & .69 & $.13^{* *}$ & $.22 * *$ & $.21 * *$ & .04 & $.38 * *$ & $.37 * *$ & $.33 * *$ & $.37 * *$ & $.22 * *$ & $.35 * *$ & $.61 * *$ & $.45^{* *}$ & .85 \\
\hline
\end{tabular}

Note. ${ }^{* *}$ Correlation is significant at the 0.01 level (two-tailed).

* Correlation is significant at the 0.05 level (two-tailed)

Note. Numbers along the top diagonal are Cronbach's alpha (reliability) coefficients of the corresponding scale.

Note. $\mathrm{N}=114$ for correlations involving coworker OCB ratings. 


\section{Correlation Analysis for H1-H3}

The Pearson correlation analysis used to test relationships between personality and work engagement in hypotheses 1a-1d were highly significant and in the predicted directions. Specifically, Hypothesis 1a proposed that conscientiousness would be positively related to work engagement. Data indicated a significant positive relationship between conscientiousness and work engagement $(r=.27)$, thus providing support for this hypothesis. Hypothesis $1 \mathrm{~b}$ proposed a positive relationship between agreeableness and work engagement. Results supported the hypothesis showing that agreeableness was significantly related to work engagement $(r=.37)$. Hypothesis $1 \mathrm{c}$ asserted that extraversion would be positively related to work engagement. Support was found for this hypothesis as extraversion was significantly related to work engagement $(r=.24)$. Lastly, to test hypothesis 1d, the relationship between neuroticism and work engagement was calculated. Again, the result supported a significant negative relationship between neuroticism and work engagement $(r=-.19)$.

Results indicated only partial support of hypotheses $2 a-2 b$. Specifically, relationships were supported using self-reported OCB, but not when using coworkerreported OCB. Hypothesis 2a proposed a positive relationship between work engagement and OCB-I. Results supported the hypothesis showing that engagement was significantly related to self-report OCB-I $(r=.15)$, whereas the relationship between engagement and coworker-report OCB-I was positive, but not significant $(r=.08)$. Similarly, hypothesis $2 \mathrm{~b}$ proposed a positive relationship between work engagement and OCB-O. Results supported the hypothesis showing that engagement was significantly related to self-report OCB-O $(r=.38)$, whereas the relationship between engagement and 
coworker-reported OCB-I was also positive, but not significant $(r=.18)$. Ultimately, although not all hypothesized relationships were significant, all showed support for positive relationship between engagement and citizenship behavior.

Hypotheses $3 \mathrm{a}-3 \mathrm{e}$ tested relationships between personality variables and OCB dimensions. In particular, hypothesis 3a proposed that conscientiousness would be positively related to OCB-O. Analyses indicated a significant positive relationship between conscientiousness and self-reported OCB-O $(r=.13)$, but not coworker-reported OCB-O $(r=.14)$, thus providing partial support for this hypothesis. It is important to note, however, that although the relationship with coworker-reported OCB-O was not significant, support exists for the positive direction of the relationship. Furthermore, the effect size for coworker-reported data was greater than that of self-reported data possibly suggesting a lack of power as a contributor to the lack of significance. This will be discussed further in a later section. To test hypothesis $3 \mathrm{~b}$, the relationship between agreeableness and OCB-I was calculated. Results showed that both self-report OCB-I ( $r$ $=.23)$ and coworker-reported OCB-I $(r=.23)$ were significantly related to agreeableness. Hypothesis $3 \mathrm{c}$ asserted that extraversion would be positively related to OCB-I. Partial support was found for this hypothesis as extraversion was significantly related to selfreported OCB-I $(r=.16)$, but not coworker-reported OCB-I $(r=.05)$. Regardless of source, however, results support the positive direction of the relationship between extraversion and OCB-I. Hypothesis $3 \mathrm{~d}$ proposed a negative relationship between neuroticism and OCB-I. Results did not support the hypothesis. Instead, neuroticism was significantly and positively related to self-report OCB-I $(r=.10)$ and nonsignificantly related to coworker-report OCB-I $(r=-.01$.$) . To test hypothesis 3 \mathrm{e}$ the 
relationship between neuroticism and OCB-O was calculated. Results did not show significance for relationships between neuroticism and either self-report OCB-O $(r=$ $.03)$ or coworker-report OCB-O $(r=.07)$, thus support for hypothesis $3 \mathrm{e}$ was not found. It is interesting to note that the relationship between neuroticism and citizenship behavior depended on the source of data. Possible explanations are discussed later in the paper.

\section{Mediation Analysis for H4a-4e}

Ten multiple regression analyses used to test hypotheses $4 a-4 e$ reported mixed results for the mediating role of work engagement in the specified relationships using self and coworker reported OCB: work engagement as a mediator between conscientiousness and OCB-O, work engagement as a mediator between agreeableness and OCB-I, work engagement as a mediator between extraversion and OCB-I, and work engagement as a mediator between neuroticism and both OCB-I and OCB-O. All hypotheses were tested using the Utrecht Work Engagement Scale (UWES; Shaufeli et al., 2002) and following Baron and Kenny's (1986) procedure for testing mediation, which tests three regression models. Specifically, the following three regression equations should be performed: first, regress the mediator on the independent variable; second, regress the dependent variable on the independent variable; and lastly, regress the dependent variable on the independent variable and the mediator. The three regressions serve to test the linkages of the mediation model. To establish mediation, the following conditions needed to be met: "First, the independent variable must affect the mediator in the first equation; second, the independent variable must be shown to affect the dependent variable in the second equation; and third, the mediator must affect the dependent variable in the third equation.” (Baron \& Kenny, 1986, p.1177). In other words, in order to establish evidence 
for mediation: 1) personality must be significantly associated with work engagement in the first equation as [i.e., $\beta$ coefficient for personality variable must be significant]; 2) personality must be significantly associated with the citizenship behavior in the second equation [i.e., $\beta$ coefficient for personality variable must be significant]; and 3) work engagement must be significantly associated with citizenship behavior, and the impact of the personality on citizenship behavior must be less after controlling for work engagement in the third equation [i.e., $\beta$ coefficient for personality must be significant at step 1 , but reduced at step 2 while the corresponding $p$-value increases; $\beta$ coefficient for engagement must be significant at step 2 , and a positive and significant $R^{2}$ change should be evident after step 2]. Detailed results of the third regression equation (i.e., step 1 and step 2) are displayed in table format for each of the hypothesized mediation relationships discussed below.

\section{Mediation Analyses for Conscientiousness, Work Engagement, and OCB-O.}

A series of regression analyses were conducted to test if work engagement mediated the relationship between conscientiousness and OCB-O, hypothesis 4a. First, work engagement was regressed on conscientiousness; conscientiousness significantly accounted for a portion of the variance in work engagement $(\beta=.27, p<.001)$, thus condition one was met. Second, OCB-O was regressed on conscientiousness; conscientiousness accounted for a significant portion of the variance in OCB-O $(\beta=.13$, $p<.01)$, thus condition two was met. To examine the last condition necessary to show support for mediation, OCB-O was regressed on both conscientiousness and work engagement. For this regression, the $\beta$ coefficient for conscientiousness was reduced from .13 to .03 , and changed to non significant $(p=.57)$. Additionally, $R^{2}$ change $=.13(p$ 
$<.001$ ), indicating that work engagement explained an additional $13 \%$ of the variance in self-reported OCB-O, when the effects of conscientiousness was statistically controlled. Evidence for the mediation of work engagement in the relationship between conscientiousness and self reports of OCB-O was found. Detailed results of the third regression analysis are presented in Table 2.

This process was done twice, first with self reported OCB-O scores and again with coworker reported OCB-O. However, for coworker reported OCB-O, although condition one was met $(\beta=.27, p<.001)$, condition two $(\beta=.14$, n.s. $)$ and condition three (see Table 2) were not met. Therefore, as defined by Baron and Kenny (1986), evidence of mediation was not found with coworker ratings.

Table 2. Hierarchical Multiple Regression Analysis of the Mediating Role of Engagement between Conscientiousness and OCB-O

Dependent Variable: OCB-O

\begin{tabular}{ccccc} 
& \multicolumn{2}{c}{ Coworker } & \multicolumn{2}{c}{ Self-Report } \\
\cline { 2 - 5 } Independent Variable & Step 1 & Step 2 & Step 1 & Step 2 \\
\hline Conscientiousness & .14 & .09 & $.13^{* *}$ & .03 \\
Work Engagement & & .16 & .02 & $.37^{* * *}$ \\
$\mathrm{R}^{2}$ at each step & .02 & .04 & & .14 \\
$\mathrm{R}^{2}$ change & & .02 & $.13^{* * *}$ \\
\hline$* p<.05 . * * p<.01 . * * * p<.001$. & & &
\end{tabular}

Mediation Analysis for Agreeableness, Work Engagement, and OCB-I.

The same series of regression analyses were conducted to test if work engagement mediated the relationship between agreeableness and OCB-I, hypothesis $4 \mathrm{~b}$. First, work 
engagement was regressed on agreeableness. Second, OCB-I was regressed on agreeableness. Last, OCB-I was regressed on both agreeableness and work engagement. For self reported OCB-I, condition one $(\beta=.37, p<.001)$ and two $(\beta=.23, p<.001$. $)$ were met. However, for condition three (see Table 3 ) although the $\beta$ coefficient for agreeableness was reduced from .23 to .20 , the significance level remained the same; further, the $R^{2}$ change was not significant $\left(R^{2}=.01, n . s.\right)$. Thus, evidence for the mediation of work engagement in the relationship between agreeableness and self reports of OCB-I was not supported. Similarly, for coworker reported OCB-I, although condition one $(\beta=.37, p<.001)$ and condition two $(\beta=.23, p<.05)$ were met, condition three (see Table 3) was not met; therefore, evidence of mediation was not found with coworker ratings.

Table 3. Hierarchical Multiple Regression Analysis of the Mediating Role of Engagement between Agreeableness and OCB-I

Dependent Variable: OCB-I

\begin{tabular}{ccccc}
\cline { 2 - 4 } Independent Variable & \multicolumn{2}{c}{ Coworker } & Step 1 & Step 2 \\
\cline { 2 - 5 } & Step 1 & Step 2 & $.23^{* * *}$ & $.20^{* * *}$ \\
\hline Agreeableness & $.23^{*}$ & $.24^{*}$ & & .08 \\
Work Engagement & & -.01 & .05 & .06 \\
$\mathrm{R}^{2}$ at each step & .05 & .05 & & .01 \\
$\mathrm{R}^{2}$ change & & .00 & &
\end{tabular}


Mediation Analysis for Extraversion, Work Engagement, and OCB-I.

The same series of regression analyses were conducted to test if work engagement mediated the relationship between extraversion and OCB-I, hypothesis 4c. Again, all three conditions were met for self reported OCB-I, but not with coworker reported. For self reported OCB-I, condition one $(\beta=.24, p<.001)$, condition two $(\beta=$ $.16, p<.001$ ), and condition three (see Table 4) were met, thus, evidence for the mediation of work engagement in the relationship between extraversion and self reported OCB-I was found. However, for coworker reported OCB-I, although condition one $(\beta=$ $.24, p<.001)$ was met, conditions two $(\beta=.05$, n.s.) and three (see Table 4$)$ were not met; therefore, evidence of mediation was not found with coworker ratings.

Table 4. Hierarchical Multiple Regression Analysis of the Mediating Role of Engagement between Extraversion and OCB-I

Dependent Variable: OCB-I

\begin{tabular}{ccccc} 
& \multicolumn{3}{c}{ Coworker } & \multicolumn{2}{c}{ Self-Report } \\
\cline { 2 - 5 } Independent Variable & Step 1 & Step 2 & Step 1 & Step 2 \\
\hline Extraversion & .05 & .03 & $.16^{* * *}$ & $.13^{* *}$ \\
Work Engagement & & .07 & .03 & $.12^{*}$ \\
$\mathrm{R}^{2}$ at each step & .00 & .01 & & .04 \\
$\mathrm{R}^{2}$ change & & $.00^{\mathrm{a}}$ & $.01^{*}$ \\
${ }^{*} p<.05 . * * p<.01 . * * * p<.001$. & & & \\
${ }^{\mathrm{a}}$ Inconsistent due to rounding.
\end{tabular}




\section{Mediation Analysis for Neuroticism, Work Engagement, and OCB-I.}

For hypothesis $4 \mathrm{~d}$, the same series of regression analyses were conducted to test if work engagement mediated the negative relationship between neuroticism and OCB-I. Given the significant positive relationship found between Neuroticism and self-reported OCB-I $(r=.10)$, although support for the hypothesized mediated relationship was not expected, analysis was performed for completeness. For self-reported OCB-I, conditions one $(\beta=. .19, p<.001)$ and two were met $(\beta=.10, \mathrm{p}<.05$. $)$. However, for condition three (see Table 5) although the $R^{2}$ change was significant $\left(R^{2}=.03, p<.001\right)$, the $\beta$ coefficient for neuroticism increased from .10 to .13 ; further, the significance level remained the same. Note that an increase in the $\beta$ coefficient for neuroticism may indicate the presence of a suppressor variable, in this case, work engagement (MacKinnon, Krull, \& Lockwood, 2000). Conger (1974, p. 36-37) defines a suppressor variable as "a variable which increases the predictive validity of another variable (or set of variables) by its inclusion in a regression equation." In other words, the magnitude of the relationship between neuroticism and OCB-I becomes larger when work engagement is included. Although shown in Table 5, a test of mediation was not necessary for the relationship between neuroticism and coworker-reported OCB-I because the variables met condition one $(\beta=-.19, p<.001)$ but not condition two $(\beta=-.01, n . s)$. Hence, these results do not fully meet the criteria defined by Baron and Kenny (1986), and therefore suggest that work engagement does not mediate the relationship between neuroticism and OCB-I with either self-report or coworker ratings. 
Table 5. Hierarchical Multiple Regression Analysis of the Mediating Role of Engagement between Neuroticism and OCB-I

Dependent Variable: OCB-I

\begin{tabular}{ccccc} 
& \multicolumn{4}{c}{ Dependent Variable: OCB-I } \\
\cline { 2 - 5 } Independent Variable & \multicolumn{3}{c}{ Coworker } & Self-Report \\
\cline { 2 - 5 } & Step 1 & Step 2 & $.10^{*}$ & Step 2 \\
\hline Neuroticism & -.01 & .01 & $.13^{* *}$ \\
Work Engagement & & .08 & .01 & $.18^{* * *}$ \\
$\mathrm{R}^{2}$ at each step & .00 & .01 & & .04 \\
$\mathrm{R}^{2}$ change & & .01 & & $.03^{* * *}$ \\
\hline
\end{tabular}

$* p<.05 .{ }^{* *} p<.01 .{ }^{* * *} p<.001$.

Mediation Analysis for Neuroticism, Work Engagement, and OCB-O.

A final series of regression analyses were conducted to test if work engagement mediated the negative relationship between neuroticism and OCB-O, hypothesis 4e. Although shown in Table 6, a test of mediation was not necessary for the relationship between neuroticism and either self or coworker reported OCB-O because the variables did not meet the second condition defined by Baron and Kenny (1986). Hence, these results suggest that work engagement does not mediate the relationship between neuroticism and OCB-O. 
Table 6. Hierarchical Multiple Regression Analysis of the Mediating Role of Engagement between Neuroticism and OCB-O

Dependent Variable: OCB-O

\begin{tabular}{ccccc} 
& \multicolumn{3}{c}{ Coworker } & \multicolumn{2}{c}{ Self-Report } \\
\cline { 2 - 5 } Independent Variable & Step 1 & Step 2 & Step 1 & Step 2 \\
\hline Neuroticism & -.06 & -.03 & .04 & $.12^{* *}$ \\
Work Engagement & & .18 & & $.40^{* * *}$ \\
$\mathrm{R}^{2}$ at each step & .00 & .04 & .00 & .16 \\
$\mathrm{R}^{2}$ change & & $.03^{\mathrm{a}}$ & $.15^{* * *}$ \\
\hline $\begin{array}{l}* \\
\text { a } p<.05 . * * p<.01 . * * * p<.001 .\end{array}$ & & &
\end{tabular}

\section{Mediation Analyses for H5 Using Distinct Work Engagement Scales}

For hypothesis 5, the five mediation analyses described above for hypotheses 4a4e were conducted again using the Maslach Burnout Inventory-General Survey (MBIGS; Maslach, et al., 1996) instead of the UWES. For those relationships in which mediation was present using the UWES, analysis consisted of a modified version of the Baron \& Kenny (1986) approach to mediation. In order to first determine whether or not mediation was found using the MBI-GS, a series of regressions were conducted in accordance with the analysis completed for hypotheses 4a-4e. Specifically, (1) work engagement [MBI-GS] was regressed on the personality dimension, (2) OCB was regressed on the personality dimension, and (3) OCB was regressed on both the personality dimension and work engagement. Lastly, a fourth regression was conducted to examine the extent to which UWES accounts for the variance in the mediation relationship over and beyond the MBI-GS. Specifically, (4) OCB was regressed on both 
work engagement measures [MBI-GS and UWES] and the personality dimension. For this regression, the $p$-values of the personality dimension and the MBI-GS were expected to increase further, therefore making them less significant. Similarly, with the additional scale added to the regression, the $\beta$ coefficients for both the personality dimension and the MBI-GS were expected to decrease further. Additionally, there should be a positive $R^{2}$ change to indicate that work engagement [UWES] explains additional variance in OCB, when the effects of the personality dimension and work engagement [MBI-GS] are statistically controlled for. Consequently, given that support for mediation using the Utrecht Work Engagement scale was a prerequisite for analysis, subsequent analysis was performed using only self-report OCB data for the following two relationships: work engagement as a mediator between conscientiousness and OCB-O, and work engagement as a mediator between extraversion and OCB-I. As preliminary analysis, there was strong convergence between the two work engagement scales $(r=.60)$ showing support for similarity in scale content. However, multicolinearity checks and correlational analysis with other variables (Table 1), suggest empirical distinctness of the two scales thus supporting continued analysis in terms of the specified mediated relationships. In addition to using a modified version of the Baron \& Kenny (1986) approach to mediation, mediation analysis using distinct measures of work engagement was also examined using the variance reduction rate (VRR). Chen and Spector (1991) introduced the VRR as an index of the proportion of shared variance for examining relationships between stressors and strain using two measures of negative affect. More specifically, the VRR can be used as a measure of the extent to which a variable accounts for shared variance between the predictor and criterion variables. The VRR is calculated as the 
squared zero-order correlation (between a predictor and a criterion) minus the squared first-order partial correlation (controlling for the mediator variable), with this difference divided by the squared zero-order correlation. As applicable to this study, for those relationships in which mediation was present using the UWES, the VRR will be calculated for both measures of work engagement in order to measure the extent to which each measure accounts for shared variance between personality and OCB. Therefore, a comparison of the two VRR values obtained for each work engagement measure will indicate the extent to which each measure affects the magnitude of the relationship between personality and OCB.

Mediation Analyses for Conscientiousness, Work Engagement, and OCB-O with Scale Comparison.

First, work engagement [MBI-GS] was regressed on conscientiousness; conscientiousness significantly accounted for a portion of the variance in work engagement [MBI-GS] $(\beta=.31, p<.001)$, thus condition one was met. Second OCB-O was regressed on conscientiousness; conscientiousness accounted for a significant portion of the variance in OCB-O $(\beta=.13, p<.01)$, thus condition two was met. Third OCB-O was regressed on both conscientiousness and work engagement [MBI-GS]. For this regression, the $\beta$ coefficient for conscientiousness was reduced from .13 to .06 , while the significance level increased to non-significance $(p>.19)$. Additionally, $R^{2}$ change $=.04$ $(p<.001)$, indicating that work engagement [MBI-GS] explained an additional $4 \%$ of the variance in self-reported OCB-O, when the effects of conscientiousness were statistically controlled. Thus, evidence for the mediation of work engagement [MBI-GS] in the relationship between extraversion and self reported OCB-I was found. Lastly, to assess 
the incremental validity of work engagement [UWES] in this mediated relationship, OCB-O was regressed on conscientiousness and work engagement [MBI-GS and UWES]. For this regression, the $\beta$ coefficient for conscientiousness decreased further from $.06(p=.18)$ to $.03(p=.55)$, while reducing in significance. Similarly, the $\beta$ coefficient for engagement [MBI-GS] decreased from .20 ( $p=.00)$ to .01 (n.s.), while the significance decreased. Additionally, $R^{2}$ change $=.09(p<.001)$, indicating that work engagement [UWES] explained an additional $9 \%$ of the variance in self-reported OCB-O, when the effects of conscientiousness and work engagement [MBI-GS] were statistically controlled. Detailed results of the fourth regression analysis are presented in Table 7. Evidence for the UWES demonstrating a stronger effect in the mediation analysis as compared to the MBI-GS between conscientiousness and self reports of OCB-O was found.

Table 7. Hierarchical Multiple Regression Analysis of the Mediating Role of Engagement between Conscientiousness and OCB-O with Scale Comparison

Dependent Variable: OCB-O (Self-Report)

\begin{tabular}{cccc}
\cline { 2 - 3 } Independent Variable & Step 1 & Step 2 & Step 3 \\
\hline Conscientiousness & $.13^{* *}$ & .06 & .03 \\
Work Engagement [MBI-GS] & & $.20^{* * *}$ & -.01 \\
Work Engagement [UWES] & & $.38^{* * *}$ \\
$\mathrm{R}^{2}$ at each step & .02 & .05 & .14 \\
$\mathrm{R}^{2}$ change & & $.04^{\mathrm{a} * * *}$ & $.09^{* * *}$ \\
$\begin{array}{l}* p<.05 . * * p<.01 . * * * p<.001 . \\
\mathrm{a} \text { Inconsistent due to rounding. }\end{array}$ & & &
\end{tabular}


Table 8 shows the zero-order correlations between self-reported conscientiousness and OCB-O as well as first-order partial correlations for the covariates UWES and MBIGS, and the variance reduction rates for the respective correlations. As can be seen, there was a positive and significant zero-order correlation between conscientiousness and OCB-O $(r=.13)$. The first-order partial correlations between conscientiousness and OCB-O when each work engagement measure was kept constant dropped when the MBIGS was controlled for $(r=.06)$, and dropped further when the UWES was controlled ( $r=$ $.03)$. Accordingly, the variance reduction rate was higher for the UWES (95\%) as compared to the MBI-GS (75\%). Results indicate that the UWES accounted for more shared variance between conscientiousness and OCB-O as compared to the MBI-GS.

Table 8. Zero- and First-Order Correlations between Conscientiousness and OCB-O with Scale Comparison

\begin{tabular}{|c|c|c|}
\hline \multirow[b]{2}{*}{$\begin{array}{c}\text { Personality factor/ Type of } \\
\text { correlation }\end{array}$} & \multicolumn{2}{|c|}{ OCB-O (Self-Report) } \\
\hline & $\mathrm{r}$ & $\begin{array}{c}\text { Variance } \\
\text { reduction rate }\end{array}$ \\
\hline \multicolumn{3}{|l|}{ Conscientiousness } \\
\hline Zero order & $.13 * *$ & \\
\hline \multicolumn{3}{|l|}{ First order } \\
\hline UWES controlled & .03 & $95 \%$ \\
\hline MBI-GS controlled & .06 & $75 \%^{\mathrm{a}}$ \\
\hline
\end{tabular}

Mediation Analysis for Extraversion, Work Engagement, and OCB-I with Scale Comparison. 
The same series of regression analyses were conducted to test if work engagement mediated the relationship between extraversion and OCB-I with both engagement scales. Since the third condition was not met, such that no support was found for the MBI-GS as a mediator between Extraversion and OCB-I, the fourth condition was not necessary in order to determine the extent to which the UWES accounts for additional variance in the mediation relationship. Nevertheless, all four steps were performed for completeness. Specifically, extraversion significantly accounted for a portion of the variance in work engagement [MBI-GS] $(\beta=.27, p<$ .001), thus condition one was met. Second, OCB-I was regressed on extraversion $(\beta=$ $.16, p<.001)$, thus condition two was met. Third, OCB-I was regressed on both extraversion and work engagement [MBI-GS]. For this regression, the $\beta$ coefficient for extraversion increased from .16 to .17 , while the significance level remained the same ( $p$ $<.001$ ). Additionally, $R^{2}$ change $=.001$ (n.s.), indicating that work engagement [MBIGS] did not explain additional variance in self-reported OCB-O, when the effects of extraversion were statistically controlled. Thus, support for the MBI-GS as a mediator in the relationship between extraversion and OCB-I was not found. Lastly, to assess the incremental validity of work engagement [UWES] in this relationship, OCB-I was regressed on extraversion and work engagement [MBI-GS and UWES]. For this regression, the $\beta$ coefficient for extraversion decreased from .17 ( $p=.001)$ to .14 (n.s.). Additionally, $R^{2}$ change $=.03(p<.001)$, indicating that work engagement [UWES] explained an additional 3\% of the variance in self-reported OCB-I, when the effects of extraversion and work engagement [MBI-GS] were statistically controlled. Detailed results of the fourth regression analysis are presented in Table 9. Evidence for the UWES 
demonstrating a stronger relationship in the mediation analysis as compared to the MBIGS in the relationship between extraversion and self reports of OCB-I was found.

Table 9. Hierarchical Multiple Regression Analysis of the Mediating Role of Engagement between Extraversion and OCB-I with Scale Comparison

\begin{tabular}{cccc} 
& \multicolumn{2}{c}{ Dependent Variable: OCB-I (Self-Report) } \\
\cline { 2 - 4 } Independent Variable & Step 1 & Step 2 & Step 3 \\
\hline Extraversion & $.16^{* * *}$ & $.17^{* * *}$ & $.15^{* *}$ \\
Work Engagement [MBI-GS] & & -.04 & -.16 \\
Work Engagement [UWES] & .03 & $.21^{* * *}$ \\
$\mathrm{R}^{2}$ at each step & & .03 & .05 \\
$\mathrm{R}^{2}$ change & & .00 & $.03^{* * *}$ \\
\hline$* p<.05 . * * p<.01 . * * * p<.001$. & & &
\end{tabular}

Table 10 shows the zero-order correlations between self-reported extraversion and OCB-I as well as first-order partial correlations for the covariates UWES and MBI-GS, and the variance reduction rates for the respective correlations. As displayed, there is a positive and significant zero-order correlation between extraversion and OCB-I $(r=.16)$. The first-order partial correlations between extraversion and OCB-I when each work engagement measure was kept constant remains the same when the MBI-GS is controlled for $(r=.16)$, but drops in magnitude and significance when the UWES is controlled ( $r=$ .13). Subsequently, the variance reduction rate is again higher for the UWES (36\%) as compared to the MBI-GS (4\%). As with the previous mediation relationship, results indicate that the UWES accounts for more shared variance between extraversion and OCB-I as compared to the MBI-GS. Unlike the relationship between conscientiousness 
and OCB-O, although the UWES accounts for more variance as compared to the MBIGS, a considerable amount of the variance between extraversion and OCB-I is not accounted for by either measure of engagement as can be seen through the first-order correlations listed below.

Table 10. Zero- and First-Order Correlations between Extraversion and OCB-I with Scale Comparison

\begin{tabular}{lcc} 
& \multicolumn{2}{c}{ OCB-I (Self-Report) } \\
\cline { 2 - 3 } $\begin{array}{c}\text { Personality factor/ Type of } \\
\text { correlation }\end{array}$ & $\mathrm{r}$ & $\begin{array}{c}\text { Variance } \\
\text { reduction rate }\end{array}$ \\
\hline $\begin{array}{l}\text { Extraversion } \\
\text { Zero order }\end{array}$ & $.16^{* * *}$ & \\
First order & & $36 \%{ }^{\mathrm{a}}$ \\
$\quad$ UWES controlled & $.13^{* *}$ & $4 \%$ \\
MBI-GS controlled & $.16^{* * *}$ & \\
\hline$* p<.05 . * * p<.01 .^{* * *} p<.001$. &
\end{tabular}

a Inconsistent due to rounding. VRR calculated using three decimal correlation values.

\section{Exploratory Analysis}

In order to more fully assess the differences between the two scales of engagement, further exploratory analysis was conducted relating to the MBI-GS. Specifically, correlations were examined between the MBI-GS and other study variables. Furthermore, all previously hypothesized mediation relationships involving the UWES were repeated with the MBI-GS for completeness.

As previously mentioned, Pearson correlation coefficients were computed to examine relationships between both measures of work engagement and personality dimensions (conscientiousness, agreeableness, extraversion, neuroticism) as well as 
OCB-I and -O. Correlation values for both scales are presented in Table 1. As can be seen, the UWES consistently showed higher relationships with citizenship behavior from all sources, whereas the MBI-GS showed consistently higher relationships with personality (with the exception of Agreeableness). Note that as part of the primary study analysis, support for mediation using the UWES was a prerequisite for analysis involving the MBI-GS. Therefore, the only mediation analyses initially performed with the MBIGS included work engagement as a mediator between conscientiousness and self-reported OCB-O, and work engagement as a mediator between extraversion and self-reported OCB-I. However, given the interesting pattern in the correlational comparison of the two scales, it was useful to further examine the differences between the two scales in terms of all hypothesized mediation relationships.

Consistent with previous mediation analyses, all relationships using the MBI-GS were performed following Baron and Kenny's (1986) procedure for testing mediation. Specifically, ten multiple regression analyses were used to the mediating role of work engagement [MBI-GS] in the specified relationships using both self and coworker reported OCB: MBI-GS as a mediator between conscientiousness and OCB-O, MBI-GS as a mediator between agreeableness and OCB-I, MBI-GS as a mediator between extraversion and OCB-I, and MBI-GS as a mediator between neuroticism and both OCBI and OCB-O.

Just as with the UWES, none of the mediated relationships were found to be significant using coworker-reported OCB data. For all five of the mediated relationships, personality was found to account for a significant portion of the variance in work engagement [MBI-GS], thus meeting condition one. However, as could be expected 
given the low correlations between personality and citizenship behavior, only agreeableness met the second condition by accounting for a significant portion of the variance in OCB-I $(\beta=.23, p<.05)$. However, when OCB-I was regressed on both agreeableness and work engagement [MBI-GS], the $\beta$ coefficient for agreeableness increased to .24 and remained significant $(p<.05)$, while the $\beta$ coefficient for work engagement [MBI-GS] was not significant $(\beta=-.04$, n.s. $)$, thus not meeting condition three. Consequently, evidence for the mediation of work engagement, specifically using the MBI-GS, in the relationship between personality and coworker-reported OCB was not found.

As with the UWES, results were more promising when these mediated relationships were examined using self-reported OCB scores. As discussed earlier, support for work engagement as a mediator between conscientiousness and self-reported OCB-O was supported using both the UWES and the MBI-GS. Alternatively, work engagement was found to be a mediator between agreeableness and self-reported OCB-I when using the UWES, but not for the MBI-GS. Lastly, the remaining three relationships which were not supported with the UWES were again, not supported using the MBI-GS. Specifically, when MBI-GS as a mediator between extraversion and OCB-I was examined, although condition one and two were met, condition three was not. As before, only conditions one and two were met when I examined the MBI-GS as a mediator between neuroticism and OCB-I. Lastly, only condition one was met when I examined the MBI-GS as a mediator between neuroticism and OCB-O. Ultimately, the exploratory analyses performed suggest no superiority of the MBI-GS over the UWES in the hypothesized relationships. 
Finally, although a composite work engagement score was used to test the study hypotheses, further exploratory analyses examined the unique contribution of each of the subscales of work engagement using the UWES: vigor, dedication, and absorption. As seen in Table 1, correlation analysis comparing overall work engagement to each subscale with other study variables revealed interesting results. In particular, as compared to overall work engagement, vigor consistently displayed stronger relationships with study variables. In addition to all the relationships that were found to be significant with overall work engagement, vigor was also found to be significantly related to coworker-reported OCB-O $(r=.33, p<.01)$. Vigor was also positively related to coworker-reported OCB-I $(r=.18)$, and although it was not found to be significant, the strength of this relationship was greater than that of vigor and self-reported OCB-I $(r=$ $.17, p<.001)$ as well as overall engagement and self-reported OCB-I $(r=.15, p<.01)$.

Despite the stronger relationships displayed through correlational analysis, when vigor was used in place of overall work engagement in the mediation relationships, results remained largely the same. Specifically, as with overall work engagement, results did not support vigor as a mediator between any personality dimension and coworkerreported OCB. As for self-reported OCB, just as was found with overall work engagement, support was found for the following two relationships: vigor as a mediator between conscientiousness and OCB-O, and vigor as a mediator between extraversion and OCB-I.

\section{Chapter V}

Discussion 
The purpose of this study was to examine work engagement as a mechanism through which a number of individual differences result in organizational citizenship behaviors in the workplace. Most research examining the antecedents of engagement has focused specifically on work-related factors and personal resources (Bakker \& Demerouti, 2008; Saks, 2006). Along this track, Bakker and Demerouti (2008) proposed a model of work engagement (see Appendix A) that includes job and personal resources as predictors of engagement. However, researchers' preoccupation with situational and resource-based antecedents of engagement has precluded examination of more stable personal antecedents, such as personality traits. Recently, researchers have started expanding Bakker and Demerouti's (2008) model of work engagement by including such interpersonal differences (Dullaghan, Loo, \& Johnson, 2010; Halbesleben, Harvey, \& Bolino, 2009; Matamala, Pace, \& Thometz, 2010).

In addition to personality traits predicting work engagement, I hypothesized that personality traits would predict both work engagement as well as individual- and organization-targeted citizenship behavior. Given that citizenship behaviors are frequently spontaneous and not task-specific, they are not often associated with situational cues in the work environment. Furthermore, whereas task behavior is often closely related to cognitive ability, contextually oriented behavior is more likely influenced by personality (Motowildo, Borman, \& Schmit, 1997). Accordingly, recent research in this domain has focused on linkages between personality dimensions and OCB. Within this research, two personality traits have emerged as predictors of OCB: conscientiousness and agreeableness (Organ \& Ryan, 1995). Surprisingly, there is relatively little research explaining why personality traits would be good predictors of 
OCB. In response to the research need for a more comprehensive model of the personality-OCB relationship, this study hypothesized work engagement as a mediator of this relationship.

This study further explored the nomological network of engagement by assessing specific Big Five personality dimensions as predictors of engagement, and citizenship behavior as an outcome. Additionally, the study assessed work engagement as a mediator to this personality-citizenship behavior relationship. Lastly, these mediated relationships were examined using two different conceptualizations of employee engagement.

All personality predictors were related to engagement with correlations ranging from small to moderate magnitude. Specifically, I found full support for hypotheses 1a1e. Results suggest that conscientiousness, agreeableness, and extraversion are all significantly and positively related to work engagement, and neuroticism is negatively related. The findings concur with previous work engagement studies that examined personality dimensions as predictors of engagement (Dullaghan, Loo, \& Johnson, 2010; Halbesleben, Harvey, \& Bolino, 2009; Langelaan, Bakker, Doornen, \& Schaufeli, 2005; Matamala, Pace, \& Thometz, 2010). Our findings suggest that in addition to organizational resources, employee disposition also predicts employee engagement. In other words, there appears to be some stable predisposition for employees to become engaged in their work. Given the recent popularity of employee engagement in the organizational setting, a considerable amount of resources are being directed towards engagement-related research and interventions. It appears that all employees, regardless 
of their personality dispositions, could reach increased levels of work engagement if interventions are appropriately tailored.

When looking at outcomes of engagement, results show mixed support for the relationship between engagement and citizenship behavior. Although citizenship behavior was assessed using both self-report and coworker-report, the relationship between engagement and OCB was only supported using self-reported OCB-I and -O. It is important to note however, that a significantly smaller coworker sample was obtained, as compared to self-report, thus differences could be impacted by insufficient power. This will be discussed further in the limitations section. Nevertheless, in line with previous research (Dullaghan, Loo, \& Johnson, 2010) results suggest a stronger relationship between engagement and OCB-O, as compared to OCB-I. It is possible that high levels of engagement to one's own work may increase one's likelihood to go above and beyond on task-related activities, while at the same time limiting the time spent interacting with others in the workplace. Thus, engaged employees, who are likely heavily immersed in task-related activities, may be more likely to engage in organizationtargeted citizenship behavior that may arise from their work tasks. For example, an engaged employee may be so absorbed and dedicated to a particular work task that they take full ownership of the task and the associated company objectives and goals beyond what is required to complete the job. Alternatively, it is unlikely that the same employee would have time to interact with colleagues, thus limiting their exposure to individualtargeted citizenship behavior opportunities such as helping others who have heavy workloads. 
Overall, there was mixed support for hypotheses 3a through 3e which examined the relationships between personality dimensions and citizenship behavior. Consistent with previous findings (Ilies et al., 2009, Dullaghan, Loo, \& Johnson, 2010), agreeableness was related to OCB-I using both self- and coworker-reports. Interestingly, although not hypothesized, agreeableness was also found to be related to OCB-O with both coworker and self-reported sources of data. It seems that higher levels of agreeableness are associated with higher levels of citizenship behavior for both individual and organizational targeted behaviors equally. It could be that individuals high on agreeableness are more willing to take-on non-task-related activities because of their desire to be likeable regardless of whom the behavior will benefit. Alternatively, in line with their need to be liked, it is possible that they are motivated to avoid conflict and negative consequences. Therefore, they are careful to adhere to expectations placed by coworkers as well as organizational norms. Turning to the other personality dimensions, results suggest conscientiousness is related to OCB-O, using self-reported data. Although not statistically significant, it is interesting to note that the magnitude of the relationship was even stronger when assessed using coworker-reported data. Thus, although statistical limitations may be impacting the significance of the finding, the magnitude of the effect size provides conceptual support for the relationship. Possible statistical factors contributing to this are discussed later in the paper. Similarly, results show support for a positive relationship between extraversion and self-reported OCB-I. Like agreeableness, although extraversion was hypothesized to have a stronger relationship with OCB-I, results suggest a slightly stronger relationship with organization-targeted citizenship behaviors. Given the high energy and outgoing 
characteristics of extroverted individuals (Costa \& McCrae, 1976), it is likely they would be more willing to engage in activities not directly prescribed by their job role. Lastly, despite research showing a negative relationship between neuroticism and performance, the results did not support a negative relationship between neuroticism and either OCB-I or -O. In fact, when examining the relationship between neuroticism and self-reported OCB-I, results show a significant positive relationship. Likewise, although not significant, the relationship between neuroticism and self-reported OCB-O was also positive in nature, whereas the relationships between neuroticism and coworker-reported OCB-I and $-\mathrm{O}$ were both negative. It seems that the source of data for citizenship behavior plays a key role in the perception of citizenship behavior prevalence. It is possible that neurotic individuals, who are more fearful and worried by nature (Costa \& McCrae, 1976), unknowingly overestimate their citizenship behaviors through their protective mechanism of overanalyzing their behavior. Similarly, as a result of their higher levels of anxiety, they may be more prone to impression-management tactics in an effort to avoid negative consequences, such as over-emphasizing their positive behavior.

Baron and Kenny's (1986) test of mediation was used to investigate the five hypotheses that predicted that work engagement would mediate the relationship between specific personality dimensions and OCB-I and -O. Results show partial support suggesting that engagement is one mechanism through which personality affects citizenship behavior. A fully mediated model was supported for conscientiousness using self-reported OCB-O. In other words, although higher levels of conscientiousness are linked to higher levels of OCB-O, the impact of this personality factor is practically nonexistent when levels of employee engagement are considered. Results suggest the 
pivotal importance of engagement for predicting organizational-targeted citizenship, regardless of an employee's level of conscientiousness. Given the substantial amount of research supporting conscientiousness as a predictor of performance (Moon et al., 2008; Organ \& Ryan, 1994, 1995; Organ \& Lingl, 1995) it is interesting to see that levels of engagement supersede personality-related forces in this case. Parallel to these findings, a study found that job satisfaction also mediates the relationship between conscientiousness and OCB-O (Ilies et al., 2009). It seems that the same conscientious employees who are likely to engage in higher levels of citizenship behavior are also the ones that benefit from high levels of engagement. Alternatively, perhaps low levels of conscientiousness in employees should not be seen as a problem so long as organizations are able to increase their levels of engagement.

In addition, a partially mediated model was supported for extraversion when using self-reports of OCB-I, suggesting that extraversion both directly and indirectly (through engagement) predicts OCB-I. In other words, although extraversion remains a significant predictor of individual-targeted citizenship behavior, this relationship is significantly decreased when engagement is accounted for. Given the strong relationship between extraversion and citizenship behavior (Moon et al., 2008; Organ \& Ryan, 1994, 1995; Organ \& Lingl, 1995) it seems unsurprising that full mediation was not found. Specifically, as a result of the inherent gregarious nature of extraverted individuals, it seems that they would be more likely to interact with those around them, and in turn help them. Yet results suggest that increasing engagement levels of individuals further increases their likelihood of displaying individual-oriented citizenship behaviors, regardless of their level of extraversion. 
Lastly, mediation was not supported when examining the agreeableness-OCB-I or the neuroticism-OCB-I and-O relationships, with either source of OCB. Although engagement did not mediate between all our predictors and criteria, it did affect a number of relationships, suggesting work engagement is a quite useful variable in the transformation of personality to citizenship performance. As a result of our findings, I suggest augmenting Bakker and Demerouti’s (2008) model of work engagement (see Appendix B) to include individual differences as antecedents, and OCBs as outcomes of engagement. Given the mixed results depending on the source of OCB score, it would be fruitful to further examine the implications of using self-report versus coworker data for these models.

Finally, this study examined the mediation models above using a second measure of work engagement. Specifically, this study used the Maslach Burnout InventoryGeneral Scale (MBI-GS; Maslach et al., 1996), which is designed to measure work engagement in terms of the polar extreme of employee burnout. In particular, this study hypothesized that the Utrecht Work Engagement Scale (UWES; Shaufeli et al., 2002) would be a stronger predictor of the aforementioned relationships as compared to the Maslach Burnout Inventory- General Scale.

Preliminary analysis of the two scales revealed a strong significant correlation, thus suggesting substantial conceptual overlap. However, as seen in Table 1, results show that although the UWES seems to be more highly correlated with OCB, the MBI-GS seems to be more highly correlated with personality variables. Notably, whereas the UWES was not significantly related to neuroticism, the MBI-GS displayed a moderatelystrong and significant relationship. Furthermore, although the UWES was shown to be 
significantly related to both self-reported OCB-I and -O, support was only found between the MBI-GS and self-reported OCB-I. Therefore, although the two scales appear to measure similar constructs, differences in predictive validity with other study variables highlight scale dissimilarities. As discussed earlier in this paper, the main difference between the two scales lies in their conceptualization of the third dimensions of work engagement. Both scales measure some form of 'energy' and 'identification as the first two dimensions, however, the UWES characterizes the third dimension as absorption (Schaufeli and Bakker, 2004), whereas the MBI-GS defines it as self-efficacy (Maslach \& Leighter, 1997). In this sense, through absorption, the UWES more closely captures behavior-specific ways of conducting work, which in turn is more closely related to behavioral outcomes, such as citizenship behavior. On the other hand, the MBI-GS, relying more on self-efficacy, addresses attitudes and beliefs about performance, which may be more closely related to individual differences than to behavioral outcomes. Ultimately, it could be the inherent way that each scale conceptualizes work engagement that creates the differing relationships with personality and OCB. Following this rationale, it seemed likely that each scale would provide a unique contribution when examined through the mediated relationships.

As a test of this idea, the incremental predictive validity of the UWES, over and above the MBI-GS was assessed for the two relationships in which support for mediation was previously found. Specifically, both scales of work engagement were assessed as mediators in the relationships between conscientiousness and OCB-O as well as extraversion and OCB-I. Results showed support for incremental validity in both relationships, suggesting that the UWES demonstrates a stronger effect as compared to 
the MBI-GS in the mediated relationships between personality and citizenship behaviors. Although both work engagement measures displayed similar relationships with the other study variables under assessment, once the two scales were assessed in unison, the UWES remained as the only mediator in the relationship between conscientiousness and self-reported OCB-O. Furthermore, the UWES explained a significant percentage of additional variance in OCB-O once the effects of conscientiousness and the MBI-GS were statistically controlled for. Thus, although both scales display work engagement as one of the mechanisms through which conscientiousness affects OCB-O, the UWES predicts more variance in citizenship behavior than the Maslach Burnout InventoryGeneral Scale.

Similar results were obtained when the mediating effects of work engagement between extraversion and self-reported OCB-I were assessed. Interestingly, however, preliminary analysis did not support work engagement as a mediator in the relationship when measured using the MBI-GS scale. This is in contrast to the partial support which was found for work engagement as a mediator when measured using the UWES (hypothesis 4c). Yet, once more, when the UWES scale was introduced to the model, support for work engagement as a mediator was found and the UWES was found to predict additional variance in OCB-I when the effects of extraversion and the MBI-GS were statistically controlled for. Thus, just as in the aforementioned relationship, the UWES displays stronger relationships with criterion variables as compared to the MBIGS.

Results imply that although the MBI-GS conceptualizes work engagement somewhat similarly to the UWES, relationships to external variables are not parallel. 
These distinctions were highlighted through the preliminary correlation analysis and again resurfaced with the mediation analyses. Given the lack of agreement in the conceptualization of work engagement, it is critical to identify how these differences impact the measurement of engagement, and in turn our research and application of the construct in the field. If in fact the UWES is a more behavior-focused measure of work engagement, whereas the MBI-GS is a more attitude-focused measure of engagement, researchers and practitioners must be aware of the impact when using and interpreting results from each scale. Alternatively, perhaps the conceptualizations of work engagement need to be reconciled, such that future measurement discrepancies are minimized. This key distinction has broad implications for researchers given that these are the two most commonly used engagement scales in the research literature.

Our exploratory examination of three-factor engagement had some interesting results. Vigor was found to be more highly related to both personality and citizenship behavior, as compared to overall work engagement. Despite the high correlations between the three facets, researchers may want to examine the utility of each facet separately, specifically vigor. If certain organizational interventions affect only one dimension of engagement, and these dimensions each predict different criteria, organizations may be more effective at accomplishing organizational objectives by focusing on engaging their employees on the dimension most related to their desired outcome rather than expending more resources trying to increase all dimensions of engagement simultaneously. Future research should continue to examine engagement at the facet level to better understand the functioning of the construct in affecting organizational objectives and outcomes. 


\section{Limitations}

Given the stronger relationships when analyzing personality and work engagement with self-reports of OCB, as opposed to coworker reports, it raises the question of whether common method/rater bias explains the correlations of these scores with self-rated personality and work engagement. Unfortunately, the coworker sample was considerably impacted by the authentification checks, resulting in a smaller sample size than originally desired. Given this, all analyses involving coworker-reported data suffered greatly because of a small sample size. Specifically, when performing statistical significance tests such as those included in the correlation and mediation analyses, a small sample size can greatly reduce the likelihood of yielding a 'significant' result. This is specifically the case for those coworker-specific effect sizes that were equal to, or greater, than significant effect sizes from self report data. According to some researchers, an individual study could reveal a meaningful relationship but statistically non-significant results due to small sample size (Cortina \& Dunlap, 1997; Schmidt, 1996; Schmidt \& Hunter, 2010). In line with this, such researchers endorse the use of point estimates of effect size instead of significance tests that rely on statistical power (Cohen, 1994; Schmidt, 1996). Follow-up studies should benefit by the use of larger samples of coworkers. Although some effect sizes decreased when the dependent variable was measured from a separate source, this would be expected given co-worker limitations in their opportunity to observe the full range of OCB demonstrated by the focal employee (Organ \& Ryan, 1995). I believe these weaker effects remain important enough to indicate support for the majority of relationships proposed. Although the present study used multiple sources for data, it was a cross-sectional design. A longitudinal design 
could be employed in future research to further investigate the causal relationships proposed in the model. Additionally, although students were required to be employed a minimum of 20 hours to be eligible to participate, future research could benefit from a true organizational sample as opposed to a working student sample. An organizational sample would not only address the limited age range present in this sample, but could also provide easier access to non-self sources of data such as coworkers or supervisors. 


\section{Practical Implications}

Employee engagement continues to capture the interest of leaders and managers across all industries. Driven by ever-increasing competitive pressures and fast-changing environments, organizations are seeking initiatives to help them maximize their human capital resources. As such, employers are investing time and money in engagementrelated considerations, assessments, and initiatives. To this point, this study has mentioned various practical considerations for applied settings. However, there are also much more pronounced applications for employee selection and training arenas.

Currently, personality predictors are being used to select employees for a number of organizational outcomes. Findings from this study offer a deeper understanding of how an organization can achieve the desired organizational goals. Since engagement has been shown to be related to positive organizational outcomes, specifically citizenship behaviors, organizations can now select for employees that are predisposed to become engaged by focusing on the personality predictors that affect job outcomes through engagement. In other words, hiring employees based on personality predictors related directly to job performance will induce positive organizational outcomes, but so too will hiring employees based on personality factors that relate to engagement. This enables organizations to broaden their selection criteria and increases the likelihood of finding high-performing job candidates that a stricter selection system based only on direct performance-related personality criteria may exclude.

Apart from influencing selection procedures, results from this study have broad implications for engagement-related interventions. As of now, most organizations focus on ways to increase engagement through organizational changes such as programs 
targeted at job resources and demands. By changing these various job characteristics, employers try to foster working conditions that facilitate employee engagement. However, results from this study and studies similar to it support a selection-based approach to employee engagement. By switching from an intervention-based focus to a selection-based focus, organizations are able to maximize their resources by being able to better predict job success early on in the selection process as opposed to trying to maximize performance on a continual basis through interventions.

Lastly, just as in the academic literature, consulting firms and human resources practitioners are not always consistent in how they measure employee engagement. Although researchers and practitioners may agree on the definition and importance of engagement, organizations are often measuring engagement through a variety of different survey items and metrics. By comparing two distinct engagement measures, this study is a step in the right direction towards achieving a reliable and effective means of assessing employee engagement.

\section{Conclusion}

In sum, this study examined how the relationships between specific personality dimensions and citizenship behavior were mediated by work engagement using two distinct measures. Results indicate that work engagement is an important mechanism operating between personality and positive organizational outcomes. Furthermore, promising results suggest workers high on a number of personality variables may be somewhat predisposed to becoming engaged. While continuing research is needed to further investigate the theoretical and practical implications of engagement, this study highlights the key role of engagement in maximizing organizational success. 


\section{References}

Allport, G. W., \& Odbert, H. S. (1933). Trait-names: A Psycho-lexical study. Psychological Monographs, 47, 171-220.

Babcock-Roberson, M. E., \& Strickland, O. J. (2010). The relationship between charismatic leadership, work engagement, and organizational citizenship behaviors. The Journal of Psychology, 144, 313-326.

Bakker, A. B., \& Demerouti, E. (2008). The Oldenburg Nurnoutr Inventory: A good alternative to measure burnout and engagement. Hauppauge, NY: Nova Science.

Bakker, A. B., Demerouti, E., \& Verbeke, W. (2004). Using the Job Demands-Resource model to predict burnout and performance. Human Resource Management , 43, 83-104.

Bakker, A., Schaufeli, W. B., Leiter, M., \& Taris, T. W. (2008). Work engagement: An emerging concept in occupational health psychology. Work \& Stress , 22, 187200.

Bakker, A.B. \& Demerouti, E. (2007). The job demands-resources model: State of the art. Journal of Managerial Psychology, 22, 309-328.

Bakker, A.B. (2009). Building engagement in the workplace. In C. Cooper \& R. Burke (Eds.), The peak performing organization. London: Routledge.

Bakker, A.B., Gierveld, J.H., \& Van Rijswijk, K. (2006). Succesfactoren bij vrouwelijke schoolleiders in het primair onderwijs: Een onderzoek naar burnout, bevlogenheid en prestaties [Success factors among female school principals in primary teaching: A study on burnout, work engagement, and performance]. Diemen, The Netherlands: Right Management Consultants.

Bakker, A.B., Hakanen, J.J., Demerouti, E. \& Xanthopoulou, D. (2007). Job resources boost work engagement particularly when job demands are high. Journal of Educational Psychology, 99, 274-284.

Barrick, M. R., \& Mount, M. K. (1991). The Big Five Personality Dimensions and Job Performance: A Meta-Analysis. Personnel Psychology , 44, 1-26.

Berry, L. M. (2003). Employee Selection. Belmont, CA: Thompson Learning Press.

Borgatta, E. F. (1964). The structure of personality characteristics. Behavioral Science, 9, 8-17.

Borman, W. C., Penner, L. A., Allen, T. D., \& Motowidlo, S. J. (2001). Personality predictors of citizenship performance. International Journal of Selection and Assessment, 9, 52-69. 
Borman, W.C., \& Motowidlo, S.J. (1993). Expanding the criterion domain to include elements of contextual performance. In N. Schmitt \& W.C. Borman (Eds.), Personnel selection in organizations (pp. 71-98). San Francisco, CA: JosseyBass.

Britt, T. W., Castro, C. A., \& Adler, A. B. (2005). Self engagement, stressors, and health: A longitudinal study. Personality and Social Psychology Bulletin, 31, 1475-1486.

Brown, S.P. (1996). A meta-analysis and review of organizational research on job involvement. Psychological Bulletin, 2, 235- 255.

Cano-García, F. J., Padilla-Muñoz, E. M., \& Carrasco-Ortiz, M. A. (2005). Personality and contextual variables in teacher burnout. Personality and Individual Differences, 38, 929-940.

Cattell, R. B. (1947). Confirmation and clarification of primary personality factors. Psychometrika , 12, 197-220.

Chen, P. Y., \& Spector, P. E. (1991). Negative affectivity as the underlying cause of correlations between stressors and strains, Journal of Applied Psychology, 76, 398-407.

Cohen, J. (1994). The Earth is round ( $\mathrm{p}<.05)$. American Psychologist, 49, 997-1003.

Conger, A. J. (1974). A revised definition for suppressor variables: A guide to their identification and interpretation. Educational Psychological Measurement, 34, $35-46$.

Costa, P.T. Jr, \& McCrae, R. R. (1988). Personality in adulthood: A six-year longitudinal study of self-reports and spouse ratings on the NEO Personality Inventory. Journal of Personality and Social Psychology,54, 853-863.

Costa, P. T. Jr., \& McCrae, R. R. (1976). Age differences in personality structure: a cluster analytic approach. Journal of Gerontology, 3, 564-70.

Costa, P., \& McCrae, R. (1992). NEO-PI-R and NEO-FFI professional manual. Odessa, FL: Psychological Assessment Resources.

Dalal, R. S. (2005). A meta-analysis of the relationship between organizational citizenship behavior and counterproductive work behavior. Journal of Applied Psychology, 90, 1241-1255.

Digman, J. M. (1990). Personality structure: Emergence of the five-factor model. Annual Review of Psychology, 41, 417-440.

Dullaghan, T. R., Loo, K., \& Johnson, R., E. (2010) Work engagement: Are some workers predisposed to become engaged? Interactive poster session at the 25 th 
Annual Conference of the Society for Industrial and Organizational Psychology, Atlanta, GA.

Dutton \& R. Quinn (Eds.), Positive organizational scholarship (pp. 163_175). San Francisco: Berrett- Koehler.

Erikson, T. J. (2005). Testimony submitted before the U.S. Senate Committee on Health, Education, Labor and Pensions, May 26.

Eysenck, H. J. (1990). Biological dimensions of personality. New York: Guilford.

Fiske, D. W. (1949). Consistency of the factorial structures of personality ratings from different sources. Journal of Abnormal and Social Psychology, 44, 329-344.

Fox, S., Spector, P. E., Goh, A., Bruursema, K., \& Kessler, S. R. (2009). The deviant citizen: Clarifying the measurement of organizational citizenship behavior and its relation to counterproductive work behavior. Loyola University Chicago.

Fredrickson, B.L. (2003). Positive emotions and upward spirals in organizations. In K. Cameron, J.

Fritzsche, B. A., \& Parrish, T. J. (2005). Theories and research on job satisfaction. In S. D. Brown \& R. W. Lent (Eds.), Career development and counseling: Putting theory and research to work (pp. 180-202). Hoboken, NJ: Wiley.

Gierveld, J. H., \& Bakker, A. B. (2005). The influence of the secretary. Diemen, The Netherlands: Manpower.

Gill, C. M., \& Hodgkinson, G. P. (2007). Development and Validation of the Five-Factor Model Questionnaire (FFMQ). Personnel Psychology, 60, 731-766.

Hakanen, J. (2002). Tyo"uupumuksesta tyo"n imuun*positiivisen tyo"hyvinvointika“sitteen ja-menetelma“n suomalaisen version validointi opetusalan organisaatiossa [From burnout to job engagement* validation of the Finnish version of an instrument for measuring job engagement (UWES) in an educational organization]. Tyo" ja Ihminen, 16, 42-58.

Hakanen, J., Bakker, A.B. \& Schaufeli, W.B. (2006). Burnout and work engagement among teachers. Journal of School Psychology, 43, 495-513.

Hakanen, J.J., Bakker, A.B. \& Demerouti, E. (2005). How dentists cope with their job demands and stay engaged: The moderating role of job resources. European Journal of Oral Sciences, 113, 479-487.

Halbesleben, J.R.B. (2010). A meta-analysis of work engagement: Relationships with burnout, demands, resources and consequences. In A.B. Bakker \& M.P. Leiter 
(Eds.), Work engagement: Recent developments in theory and research. New York: Psychology Press.

Halbesleben, J. R., Harvey, J., \& Bolino, M. C. (2009). Too engaged? A conservation of resources view of the relationship between work engagement and work interference with family. Journal of Applied Psychology. 94, 1452-1465.

Hallberg, U. E., \& Schaufeli, W. B. (2006). “Same same” but different? Can work engagement be discriminated from job involvement and organizational commitment? European Psychologist, 11, 119-127.

Hobfoll, S.E., Johnson, R.J., Ennis, N. \& Jackson, A.P. (2003). Resource loss, resource gain, and emotional outcomes among inner city women. Journal of Personality and Social Psychology, 84, 632-643.

Hogan, R. (1986). Manual for the Hogan Personality Inventory. Minneapolis: National Computer Systems.

Hurtz, G. M., \& Donovan, J. J. (2000). Personality and job performance: The Big Five revisited. Journal of Applied Psychology, 85, 869-879.

Ilies, R., Fulmer, I. S., Spitzmuller, M., \& Johnson, M. D. (2009). Personality and citizenship behavior: The mediating role of job satisfaction. Journal of Applied Psychology, 94, 945-959.

Ilies, R., Nahrgang, J., \& Morgeson, F. P. (2007). Leader-member exchange and citizenship behaviors: A meta-analysis. Journal of Applied Psychology, 92, 269 277.

Judge, T. A., Erez, A., \& Bono, J. E. (1998). The power of being positive: The relation between positive self-concept and job performance. Human Performance, 11, $167-187$.

Judge, T.A., Bono, J.E., Erez, A. \& Locke, E.A. (2005). Core self-evaluations and job and life satisfaction: The role of self-concordance and goal attainment. Journal of Applied Psychology, 90, 257-268.

Judge, T.A., Van Vianen, A.E.M. \& De Pater, I. (2004). Emotional stability, core selfevaluations, and job outcomes: A review of the evidence and an agenda for future research. Human Performance, 17, 325-346.

Kahn, W. A. (1990). Psychological conditions of personal engagement and disengagement at work. Academy of Management , 33, 692-724.

Kahn, W. A. (1992). To be fully there: Psychological presence at work. Human Relations , 45, 321-349. 
Kanungo, R.N. (1979). The concepts of alienation and involvement revisited.

Psychological Bulletin, 86, 119-138.

Kaplan, S., Bradley, J. C., Luchman, J. N., \& Haynes, D. (2009). On the role of positive and negative affectivity in job performance: A meta-analytic investigation. Journal of Applied Psychology, 94, 162-176.

Kim H. J., Shin K. H., \& Swanger, N. (2009). Burnout and engagement: A comparative analysis using the Big Five personality dimensions. International Journal of Hospitality Management, 28, 96-104.

Koyuncu, M., Burke, R.J. \& Fiksenbaum, L. (2006). Work engagement among women managers and professionals in a Turkish bank: Potential antecedents and consequences. Equal Opportunities International, 25, 299-310.

Langelaan, S., Bakker, A. B., Van Doornen, L., \& Schaufeli, W. (2006). Burnout and work engagement: Do individual differences make a difference? Personality and Individual Differences , 40, 521-532.

Luthans, F., \& Youssef, C.M. (2007). Emerging positive organizational behavior. Journal of Management, 33, 321-349.

Macey, W. H., \& Schneider, B. (2008). The meaning of employee engagement. Industrial and Organizational Psychology, 1, 3-30.

MacKinnon, D. P., Krull, J. L., Lockwood, C. M. (2000). Equivalence of the Mediation, Confounding and Suppression Effect. Prevention Science, 1, 173-181.

Maslach, C., Jackson, S. E., \& Leiter, M. P. (1996). Maslach Burnout Inventory. (3rd ed.). Palo Alto, CA: Consulting Psychologists Press.

Maslach, C., \& Leiter, M. P. (1997). The truth about burnout: How organizations cause personal stress and what to do about it. San Francisco, CA: Jossey-Bass.

Maslach, C., Schaufeli, W. B., \& Leiter, M. P. (2001). Job Burnout. Annual Review of Psychology, 20, 397-422.

Matamala, A. C., Pace, V. L., \& Thometz, H. (2010, April). Work engagement as a mediator between personality and citizenship behavior. Interactive poster session at the 25th Annual Conference of the Society for Industrial and Organizational Psychology, Atlanta, GA.

Mauno, S., Kinnunen, U. \& Ruokolainen, M. (2007). Job demands and resources as antecedents of work engagement: A longitudinal study. Journal of Vocational Behavior, 70, 149-171. 
Meyer, J. P., \& Allen, N. J. (1997). Commitment in the workplace: Theory, research, and application. London: Sage.

Mills, L. B., \& Huebner, E. S. (1998). A prospective study of personality characteristics, occupational stressors, and burnout among school psychology practitioners. Journal of School Psychology, 36, 103-120.

Moon, H., Hollenbeck, J. R., Marinova, S., \& Humphrey, S. E. (2008). Beneath the surface: Uncovering the relationship between extraversion and organizational citizenship behavior through a facet approach. International Journal of Selection and Assessment. 16, 143-154.

Morgeson, F. P., Reider, M. H., \& Campion, M. A. (2005). Selecting individuals in team settings: The important of social skills, personality characteristics, and teamwork knowledge. Personnel Psychology, 58, 583-611.

Motowidlo, S. J., Borman, W. C., \& Schmit, M. J. (1997). A theory of individual differences in task and contextual performance. Human Performance, 10, 71-83.

Motowidlo, W. C., \& Van Scotter, J. R. (1994). Evidence that task performance should be distinguished from contextual performance. Journal of Applied Psychology, $79,475-480$.

Mowday, R.T. (1998). Reflections on the study and relevance on organizational commitment. Human Resource Management Review, 4, 387-401.

Norman, W. T. (1963). Toward and adequate taxonomy of personality attributes: Replicated factor structure in peer nomination personality ratings. Journal of Abnormal and Social Psychology, 66, 574-583.

Organ, D. W. (1988). Organizational citizenship behavior: The good soldier syndrome. Lexington, MA: Lexington Books.

Organ, D. W. (1994). Personality and organizational citizenship behavior. Journal of Management. 20, 465-478.

Organ, D. W., \& Lingl, A. (1995). Personality, satisfaction, and organizational citizenship behavior. The Journal of Social Psychology. 135, 339-350.

Organ, D. W., \& Ryan, K. (1995). A meta-analytic review of attitudinal and dispositional predictors of organizational citizenship behavior. Personnel Psychology, 48, 755802.

Podsakoff, N.P., Whiting, S.W., Podsakoff, P.M., \& Blume, B.D. (2009). Individual and organizational-level consequences of organizational citizenship behaviors: A meta-analysis. Journal of Applied Psychology, 94, 122-141. 
Podsakoff, P. M., MacKenzie, S. B., Paine, J. B., \& Bachrach, D. G. (2000). Organizational citizenship behavior: A critical review of the theoretical and empirical literature and suggestions for future research. Journal of Management, 26, 513-563.

Rich, B. L., LePine, J. A., \& Crawford, E. R. (2010). Job engagement: Antecedents and effects on job performance. Academy of Management Journal, 53, 617-635.

Rothbard, N. P. (2001). Enriching or depleting? The dynamics of engagement in work and family roles. Administrative Science Quarterly, 46, 655-684.

Rothmann, S., \& Storm, K. (2003, May). Work engagement in the South African Police Service. Paper presented at the 11th European Congress of Work and Organizational Psychology, Lisbon, Portugal.

Saks, A. M. (2006). Antecedents and consequences of employee engagement. Journal of Managerial Psychology, 21, 600-619.

Salanova, M., Agut, S. \& Peiro', J.M. (2005). Linking organizational resources and work engagement to employee performance and customer loyalty: The mediation of service climate. Journal of Applied Psychology, 90, 1217-1227.

Schaufeli, W. B., \& Bakker, A. B. (2004). Job demands, job resources, and their relationship with burnout and engagement: A multi-sample study. Journal of Organizational Behavior, 25, 293-315.

Schaufeli, W. B., Salanova, M., Gonzalez-Roma, V., \& Bakker, A. B. (2002). The measurement of engagement and burnout: A two sample confirmatory analytic approach. Journal of Happiness Studies , 3, 71-92.

Schaufeli, W.B. \& Salanova, M. (2007). Work engagement: An emerging psychological concept and its implications for organizations. In S.W. Gilliland, D.D. Steiner \& D.P. Skarlicki (Eds.), Research in social issues in management: Vol. 5. Managing social and ethical issues in organizations. Greenwich, CT: Information Age Publishers.

Schaufeli, W.B., \& Bakker, A.B. (2003). UWES*Utrecht Work Engagement Scale: test manual. Unpublished manuscript, Department of Psychology, Utrecht University.

Schaufeli, W.B., Bakker, A.B., \& Van Rhenen, W. (2009). How changes in job demands and resources predict burnout, work engagement, and sickness absenteeism. Journal of Organizational Behavior, 30, 893-917.

Shaufeli, W. B., Bakker, A. B., \& Salanova, M. (2006). The measurement of work engagement with a short questionnaire: A cross-national study. Educational and Psychological Measurement , 66, 701-716. 
Schaufeli, W.B., Taris, T.W. \& Bakker, A.B. (2006). Dr. Jekyll and Mr. Hyde: On the differences between work engagement and workaholism. In R.J. Burke (Ed.), Research companion to working time and work addiction (pp. 193_217). Northampton: Edward Elgar.

Schmidt, F. L. (1996). Statistical significance testing and cumulative knowledge in psychology: Implications for training of researchers. Psychological Methods, 1, 115-129.

Shimazu, A., Schaufeli, W.B., Kosugi, S., Suzuki, A., Nashiwa, H., Kato, A., et al. (2008). Work engagement in Japan: Development and validation of the Japanese version of the Utrecht Work Engagement Scale. Applied Psychology: An International Review, 57, 510_523.

Shin, K. (2003). Job engagement and job burnout in a South Korean sample. Unpublished doctoral dissertation, Kansas State University, Manhattan.

Shirom, A. (2003). Feeling vigorous at work? The construct of vigor and the study of positive affect in organizations. In D. Ganster \& P. L. Perrewe (Eds.). Research in organizational stress and well-being. (Vol. 3, pp. 135-165). Greenwich, CT: JAI Press.

Storm, K., \& Rothmann, I. (2003). A psychometric analysis of the Utrecht Work Engagement Scale in the South African police service. South African Journal of Industrial Psychology, 29, $62 \_70$.

Tett, R. P., Jackson, D. N., \& Rothstein, N. (1991). Personality measures as predictors of job performance: A meta-analystic review. Personnel Psychology , 44, 703-742.

Wefald, A. J., \& Downey, R. G. (2009). Construct dimensionality of engagement and its relation with satisfaction. The Journal of Psychology, 143, 91-111.

Williams, L. J., \& Anderson, S. E. (1991). Job satisfaction and organizational commitment as predictors of organizational citizenship and in-role behaviors. Journal of Management, 17, 601-617.

Xanthopoulou, D., Bakker, A.B., Demerouti, E. \& Schaufeli, W.B. (2007). The role of personal resources in the job demands-resources model. International Journal of Stress Management, 14, 121-141.

Xanthopoulou, D., Bakker, A.B., Demerouti, E., \& Schaufeli, W.B. (2008).Work engagement: A cycle of job and personal resources. Manuscript submitted for publication.

Yi-Wen, Z., \& Yi-Qun, C. (2005). The Chinese version of the Utrecht Work Engagement Scale: An examination of reliability and validity. Chinese Journal of Clinical Psychology, 13, 268-270. 
Zellars, K. L., Hochwarter, W. A., Perrewe', P. L., Hoffman, N., \& Ford, E. W. (2004). Experiencing job burnout: The roles of positive and negative traits and states. Journal of Applied Social Psychology, 34, 887-911. 
Appendix A

Bakker \& Demerouti's (2007) Model of Work Engagement

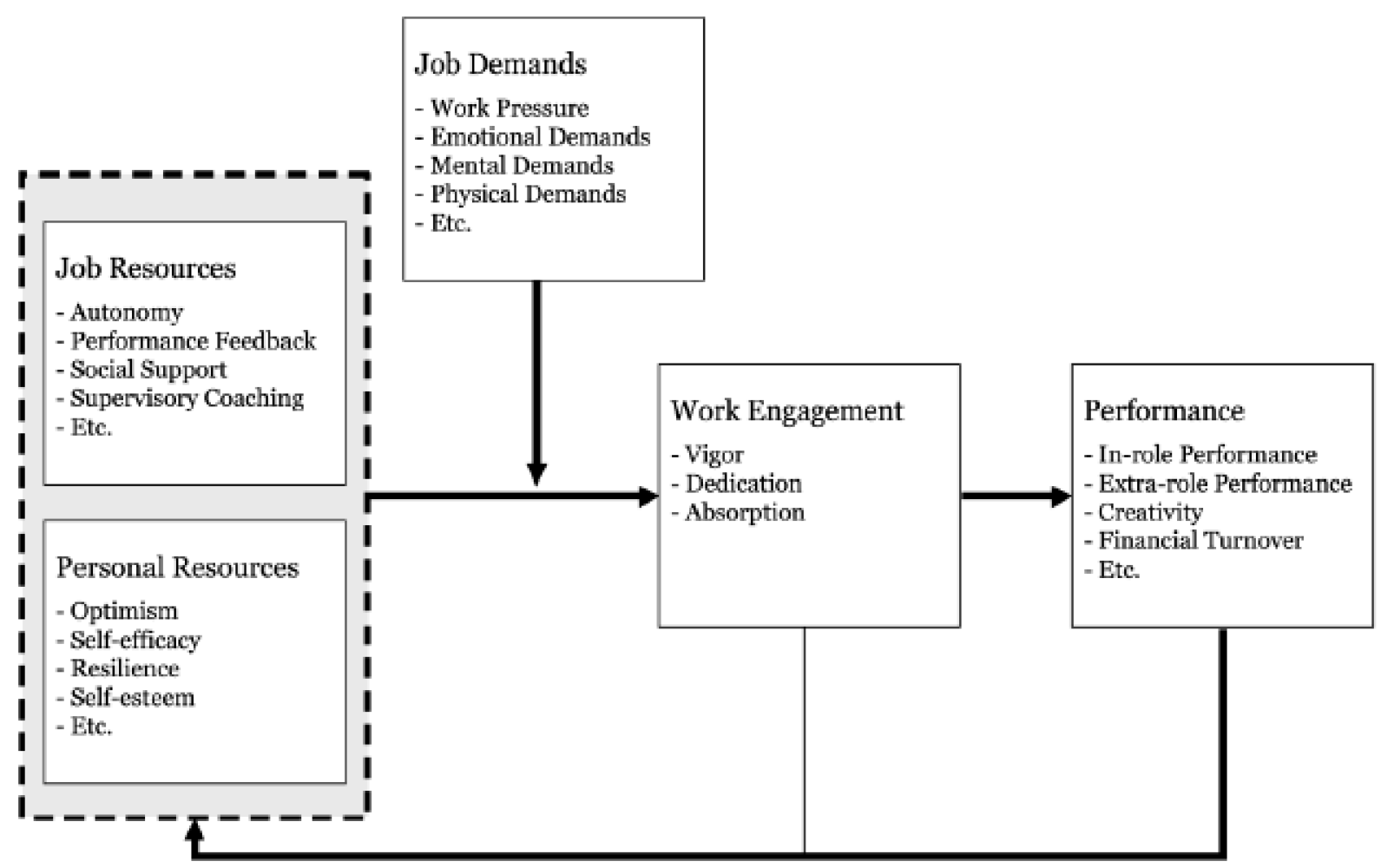


Appendix B

Proposed Revised Model of Work Engagement

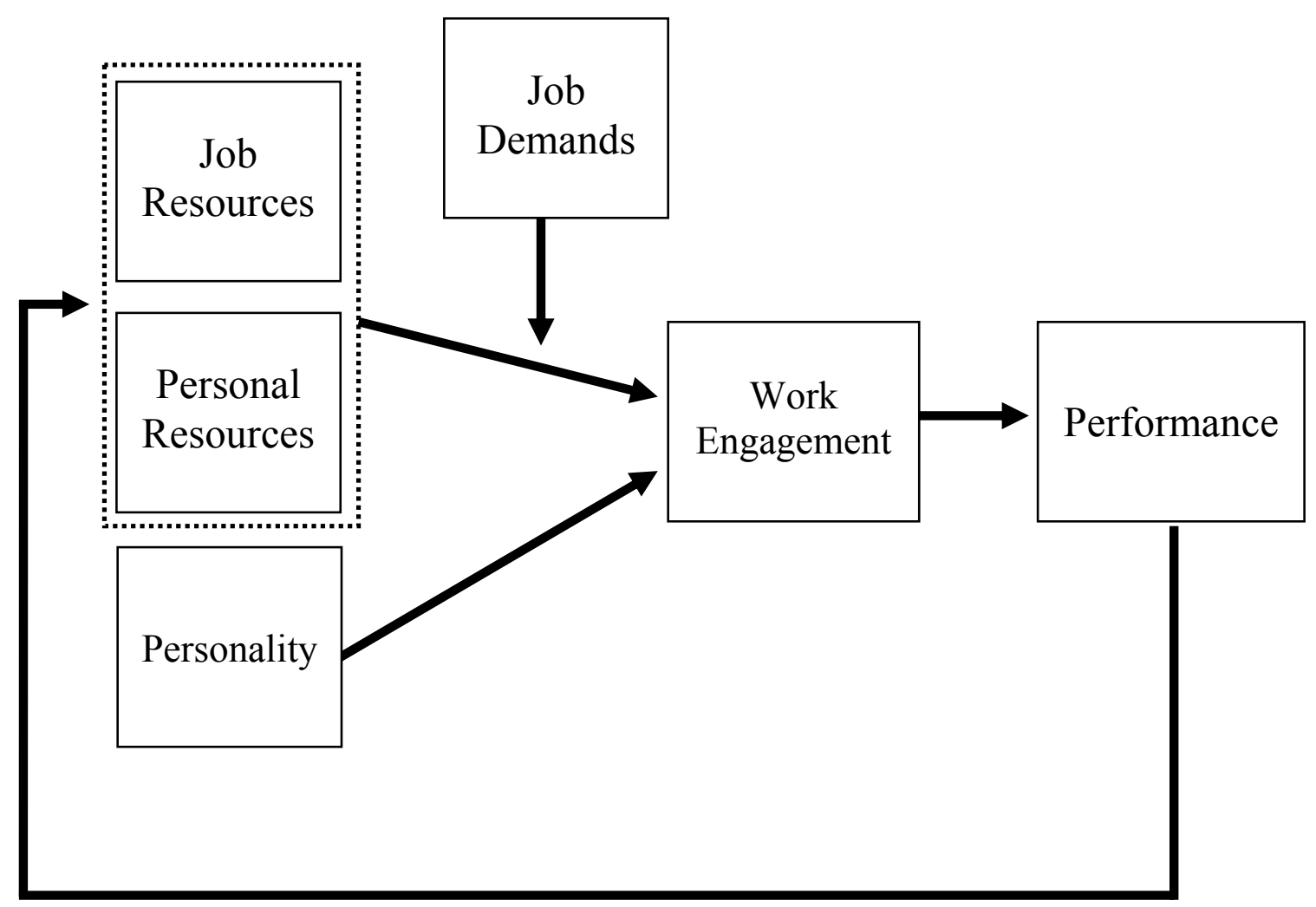


Appendix C

Select Hypothesized Relationship

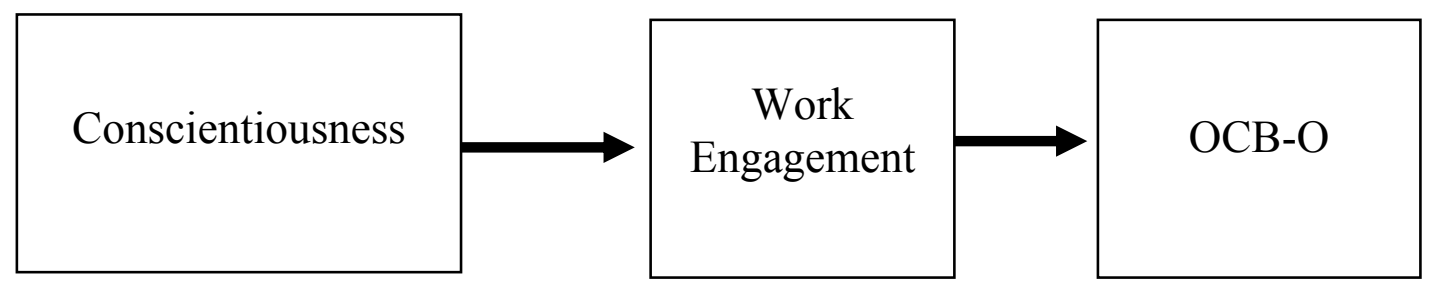


Appendix D

Employee Survey

\section{Consent to Participate in a Research Study}

\section{Exploring Personality Traits and Work Experiences: IRB \# 101410-01}

You are being asked to be in a research study. The investigator of this study is Alejandra Matamala and she is a graduate student at FIU. The study will include about 400 students who are employed at least half-time and a coworker for each participant. Your participation will require about 30 minutes of your time. The goal of this study is to explore the relationships among personality traits and general behavior within work contexts.

If you decide to be a part of the study we will provide you with the website login information to participate via the internet. You will be asked to complete an online survey. You will be provided instructions on how to complete the survey online. Please read instructions carefully and follow them closely. You will be asked to answer general questions about: 1) your personality; 2) your general attitudes within work contexts; and 3 ) your general behavior within work contexts. Lastly, you will be asked to have one of your coworkers complete an online survey about your general experiences within work contexts.

The online survey will be similar to using a computer for work or play. We do not expect any harm to you by being in the study. Your survey will be identified by a random number not your name. All of your answers are private and will not be shared with anyone unless required by law. You may ask questions about the study at any time. If you choose not to participate no one will be upset with you. You may skip any questions that you do not want to answer. You may also choose to stop your participation before your finish the survey. There is no cost or payment to you as a subject. However, you will receive 1 Sona point for completing the online survey yourself, and 1 additional Sona point for having a coworker complete the other online survey.

Your honest answers will help researchers and employers understand how personality relates to job attitudes and experiences. Your data will be compared to data of other subjects. We will present research results about the group of participants only, without any identification of individual participants or their specific data.

If you would like more information about this research after you are done, you can contact me via email at amata005@fiu.edu or Dr. Victoria Pace via email at vpace@fiu.edu. If you feel that you were mistreated or would like to talk with someone about your rights as a volunteer in this research study you may contact Dr. Patricia Price, the Chairperson of the FIU Institutional Review Board at 305-348-2618 or 305-348-2494. 
If you would like to participate, please select "Yes, I agree to participate" and continue to the next page to complete the survey. If you would not like to participate, please select "No, I do not agree to participate" and close the browser window.

Please select one:

C Yes, I agree to participate

C No, I do not agree to participate

\section{Section One}

This assessment is made up of a list of words that describe various ways people behave. All that you have to do is decide how well each word describes you and the way that you usually behave when you are at work. There are five possible answers;

- Not like me at work

- Not much like me at work

- Neutral

- Quite like me at work

- Very like me at work

Do not spend too much time thinking about each word because your first impression is usually best. There are no right or wrong answers, it's your opinion that matters. Please make sure that you respond to every word.

When you are sure that you understand these instructions, please click NEXT.

\begin{tabular}{|c|c|}
\hline How well does each word describe you at work? & 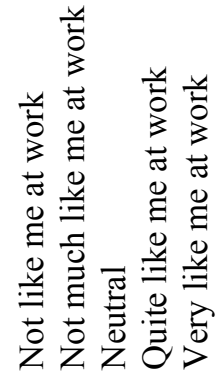 \\
\hline 1. Sensitive & $\begin{array}{lllll} & 2 & 3 & 4 & 5 \\
\end{array}$ \\
\hline 2. $\quad$ Nice & $\begin{array}{lllll}1 & 2 & 3 & 4 & 5 \\
\end{array}$ \\
\hline 3. Warm & $\begin{array}{lllll}1 & 2 & 3 & 4 & 5\end{array}$ \\
\hline 4. $\quad$ Welcoming & $\begin{array}{lllll} & 2 & 3 & 4 & 5 \\
\end{array}$ \\
\hline 5. Supportive & $\begin{array}{lllll}1 & 2 & 3 & 4 & 5 \\
\end{array}$ \\
\hline 6. $\quad$ Caring & $\begin{array}{lllll}1 & 2 & 3 & 4 & 5 \\
\end{array}$ \\
\hline 7. Generous & $\begin{array}{lllll} & 2 & 3 & 4 & 5\end{array}$ \\
\hline 8. $\quad$ Kind & $\begin{array}{lllll}1 & 2 & 3 & 4 & 5 \\
\end{array}$ \\
\hline 9. Thoughtful & $\begin{array}{lllll}1 & 2 & 3 & 4 & 5 \\
\end{array}$ \\
\hline 10. Unemotional & $\begin{array}{lllll} & 2 & 3 & 4 & 5 \\
\end{array}$ \\
\hline 11. Companionable & $\begin{array}{lllll}1 & 2 & 3 & 4 & 5 \\
\end{array}$ \\
\hline 12. Inflexible & $\begin{array}{lllll}1 & 2 & 3 & 4 & 5 \\
\end{array}$ \\
\hline
\end{tabular}




\begin{tabular}{|c|c|}
\hline How well does each word describe you at work? & 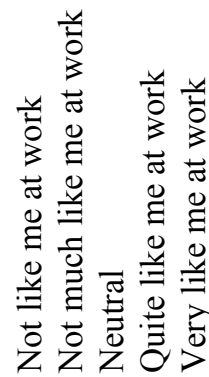 \\
\hline 13. Cooperative & $\begin{array}{lllll}1 & 2 & 3 & 4 & 5\end{array}$ \\
\hline 14. Unhelpful & $\begin{array}{lllll}1 & 2 & 3 & 4 & 5 \\
\end{array}$ \\
\hline 15. Tolerant & $\begin{array}{lllll}1 & 2 & 3 & 4 & 5\end{array}$ \\
\hline 16. Gentle & $\begin{array}{lllll}1 & 2 & 3 & 4 & 5\end{array}$ \\
\hline 17. Conscientious & $\begin{array}{lllll}1 & 2 & 3 & 4 & 5 \\
\end{array}$ \\
\hline 18. Accurate & $\begin{array}{lllll}1 & 2 & 3 & 4 & 5\end{array}$ \\
\hline 19. Unsystematic & $\begin{array}{lllll}1 & 2 & 3 & 4 & 5 \\
\end{array}$ \\
\hline 20. Clumsy & $\begin{array}{lllll}1 & 2 & 3 & 4 & 5 \\
\end{array}$ \\
\hline 21. Sloppy & $\begin{array}{lllll}1 & 2 & 3 & 4 & 5\end{array}$ \\
\hline 22. Precise & $\begin{array}{lllll}1 & 2 & 3 & 4 & 5 \\
\end{array}$ \\
\hline 23. Punctual & $\begin{array}{lllll}1 & 2 & 3 & 4 & 5 \\
\end{array}$ \\
\hline 24. Decisive & $\begin{array}{lllll}1 & 2 & 3 & 4 & 5\end{array}$ \\
\hline 25. Untidy & $\begin{array}{lllll}1 & 2 & 3 & 4 & 5 \\
\end{array}$ \\
\hline 26. Erratic & $\begin{array}{lllll}1 & 2 & 3 & 4 & 5 \\
\end{array}$ \\
\hline 27. Careless & $\begin{array}{lllll}1 & 2 & 3 & 4 & 5 \\
\end{array}$ \\
\hline 28. Exact & $\begin{array}{lllll}1 & 2 & 3 & 4 & 5 \\
\end{array}$ \\
\hline 29. Systematic & $\begin{array}{lllll}1 & 2 & 3 & 4 & 5 \\
\end{array}$ \\
\hline 30. Tidy & $\begin{array}{lllll}1 & 2 & 3 & 4 & 5\end{array}$ \\
\hline 31. Painstaking & $\begin{array}{lllll}1 & 2 & 3 & 4 & 5 \\
\end{array}$ \\
\hline 32. Disorganized & $\begin{array}{lllll}1 & 2 & 3 & 4 & 5 \\
\end{array}$ \\
\hline 33. Curious & $\begin{array}{lllll}1 & 2 & 3 & 4 & 5\end{array}$ \\
\hline 34. Expressive & $\begin{array}{lllll}1 & 2 & 3 & 4 & 5\end{array}$ \\
\hline 35. Original & $\begin{array}{lllll}1 & 2 & 3 & 4 & 5\end{array}$ \\
\hline 36. Normal & $\begin{array}{lllll}1 & 2 & 3 & 4 & 5\end{array}$ \\
\hline 37. Ordinary & $\begin{array}{lllll}1 & 2 & 3 & 4 & 5\end{array}$ \\
\hline 38. Unconventional & $\begin{array}{lllll}1 & 2 & 3 & 4 & 5\end{array}$ \\
\hline 39. Conforming & $\begin{array}{lllll}1 & 2 & 3 & 4 & 5\end{array}$ \\
\hline 40. Innovative & $\begin{array}{lllll}1 & 2 & 3 & 4 & 5\end{array}$ \\
\hline 41. Imaginative & $\begin{array}{lllll}1 & 2 & 3 & 4 & 5\end{array}$ \\
\hline 42. Artistic & $\begin{array}{lllll} & 2 & 3 & 4 & 5\end{array}$ \\
\hline 43. Traditional & $\begin{array}{lllll}1 & 2 & 3 & 4 & 5\end{array}$ \\
\hline 44. Conventional & $\begin{array}{lllll}1 & 2 & 3 & 4 & 5\end{array}$ \\
\hline 45. Unique & $\begin{array}{lllll}1 & 2 & 3 & 4 & 5\end{array}$ \\
\hline 46. Creative & $\begin{array}{lllll}1 & 2 & 3 & 4 & 5 \\
\end{array}$ \\
\hline 47. Average & $\begin{array}{lllll}1 & 2 & 3 & 4 & 5\end{array}$ \\
\hline 48. Orthodox & $\begin{array}{lllll}1 & 2 & 3 & 4 & 5\end{array}$ \\
\hline 49. Wary & $\begin{array}{lllll}1 & 2 & 3 & 4 & 5 \\
\end{array}$ \\
\hline 50. Introverted & $\begin{array}{lllll}1 & 2 & 3 & 4 & 5 \\
\end{array}$ \\
\hline 51. Meek & $\begin{array}{lllll}1 & 2 & 3 & 4 & 5\end{array}$ \\
\hline 52. Optimistic & $\begin{array}{lllll}1 & 2 & 3 & 4 & 5 \\
\end{array}$ \\
\hline 53. Boastful & $\begin{array}{lllll}1 & 2 & 3 & 4 & 5 \\
\end{array}$ \\
\hline 54. Daring & $\begin{array}{lllll}1 & 2 & 3 & 4 & 5\end{array}$ \\
\hline
\end{tabular}




\begin{tabular}{|c|c|}
\hline How well does each word describe you at work? & 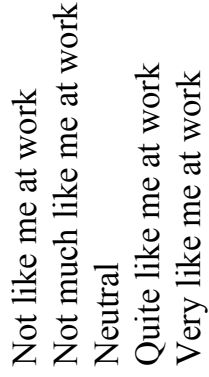 \\
\hline 55. Shy & $\begin{array}{lllll}1 & 2 & 3 & 4 & 5\end{array}$ \\
\hline 56. Brave & $\begin{array}{lllll}1 & 2 & 3 & 4 & 5\end{array}$ \\
\hline 57. Happy & $\begin{array}{lllll}1 & 2 & 3 & 4 & 5\end{array}$ \\
\hline 58. Assertive & $\begin{array}{lllll}1 & 2 & 3 & 4 & 5 \\
\end{array}$ \\
\hline 59. Cautious & $\begin{array}{lllll}1 & 2 & 3 & 4 & 5\end{array}$ \\
\hline 60. Outgoing & $\begin{array}{lllll}1 & 2 & 3 & 4 & 5 \\
\end{array}$ \\
\hline 61. Bold & $\begin{array}{lllll}1 & 2 & 3 & 4 & 5\end{array}$ \\
\hline 62. Talkative & $\begin{array}{lllll}1 & 2 & 3 & 4 & 5 \\
\end{array}$ \\
\hline 63. Quiet & $\begin{array}{lllll}1 & 2 & 3 & 4 & 5 \\
\end{array}$ \\
\hline 64. Pessimistic & $\begin{array}{lllll}1 & 2 & 3 & 4 & 5\end{array}$ \\
\hline 65. Anxious & $\begin{array}{lllll}1 & 2 & 3 & 4 & 5\end{array}$ \\
\hline 66. Pushy & $\begin{array}{lllll}1 & 2 & 3 & 4 & 5 \\
\end{array}$ \\
\hline 67. Dominant & $\begin{array}{lllll}1 & 2 & 3 & 4 & 5 \\
\end{array}$ \\
\hline 68. Aggressive & $\begin{array}{lllll}1 & 2 & 3 & 4 & 5\end{array}$ \\
\hline 69. Jealous & $\begin{array}{lllll} & 2 & 3 & 4 & 5\end{array}$ \\
\hline 70. Tough-minded & $\begin{array}{lllll}1 & 2 & 3 & 4 & 5 \\
\end{array}$ \\
\hline 71. Picky & $\begin{array}{lllll}1 & 2 & 3 & 4 & 5 \\
\end{array}$ \\
\hline 72. Relaxed & $\begin{array}{lllll}1 & 2 & 3 & 4 & 5 \\
\end{array}$ \\
\hline 73. Thick-skinned & $\begin{array}{lllll}1 & 2 & 3 & 4 & 5\end{array}$ \\
\hline 74. Impatient & $\begin{array}{lllll}1 & 2 & 3 & 4 & 5 \\
\end{array}$ \\
\hline 75. Irritable & $\begin{array}{lllll}1 & 2 & 3 & 4 & 5\end{array}$ \\
\hline 76. Grumpy & $\begin{array}{lllll}1 & 2 & 3 & 4 & 5\end{array}$ \\
\hline 77. Sarcastic & $\begin{array}{lllll}1 & 2 & 3 & 4 & 5\end{array}$ \\
\hline 78. Stressed & $\begin{array}{lllll} & 2 & 3 & 4 & 5\end{array}$ \\
\hline 79. Critical & $\begin{array}{lllll}1 & 2 & 3 & 4 & 5\end{array}$ \\
\hline 80. Moody & $1 \quad 2 \quad 3 \quad 4 \quad 5$ \\
\hline
\end{tabular}

\section{Section Two}

\begin{tabular}{|c|c|}
\hline $\begin{array}{l}\text { Please indicate how frequently you experience the following at } \\
\text { work: }\end{array}$ & 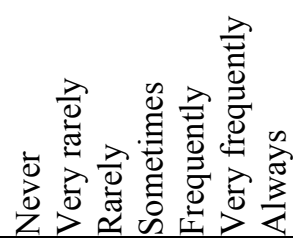 \\
\hline 1. When I get up in the morning, I feel like going to work. & $123 \quad 4 \quad 567$ \\
\hline 2. At my work, I feel bursting with energy. & $\begin{array}{lllllll}1 & 2 & 3 & 4 & 5 & 6 & 7 \\
\end{array}$ \\
\hline $\begin{array}{l}\text { 3. At my work I always persevere, even when things to do not go } \\
\text { well. }\end{array}$ & $\begin{array}{lllllll}1 & 2 & 3 & 4 & 5 & 6 & 7\end{array}$ \\
\hline 4. I can continue working for very long periods at a time & $\begin{array}{lllllll}1 & 2 & 3 & 4 & 5 & 6 & 7\end{array}$ \\
\hline
\end{tabular}




\begin{tabular}{|l|rllllll|}
\hline 5. At my job, I am very resilient, mentally. & 1 & 2 & 3 & 4 & 5 & 6 & 7 \\
\hline 6. At my job I feel strong and vigorous. & 1 & 2 & 3 & 4 & 5 & 6 & 7 \\
\hline 7. To me, my job is challenging. & 1 & 2 & 3 & 4 & 5 & 6 & 7 \\
\hline 8. My job inspires me. & 1 & 2 & 3 & 4 & 5 & 6 & 7 \\
\hline 9. I am enthusiastic about my job. & 1 & 2 & 3 & 4 & 5 & 6 & 7 \\
\hline 10. I am proud on the work that I do. & 1 & 2 & 3 & 4 & 5 & 6 & 7 \\
\hline 11. I find the work that I do full of meaning and purpose. & 1 & 2 & 3 & 4 & 5 & 6 & 7 \\
\hline 12. When I am working, I forget everything else around me. & 1 & 2 & 3 & 4 & 5 & 6 & 7 \\
\hline 13. Time flies when I am working. & 1 & 2 & 3 & 4 & 5 & 6 & 7 \\
\hline 14. I get carried away when I am working. & 1 & 2 & 3 & 4 & 5 & 6 & 7 \\
\hline 15. It is difficult to detach myself from my job. & 1 & 2 & 3 & 4 & 5 & 6 & 7 \\
\hline 16. I am immersed in my work. & 1 & 2 & 3 & 4 & 5 & 6 & 7 \\
\hline 17. I feel happy when I am working intensely. & 1 & 2 & 3 & 4 & 5 & 6 & 7 \\
\hline
\end{tabular}

\section{Section Three}

\section{$* * *$ This section omitted for copyright reasons $* * *$}

\section{Section Four}

\begin{tabular}{|c|c|}
\hline How often have you done each of the following things on your present job? & 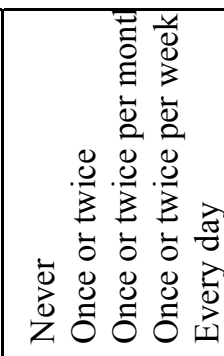 \\
\hline $\begin{array}{l}\text { 1. Drove, escorted, or entertained company guests, clients, or out-of-town } \\
\text { employees. }\end{array}$ & \begin{tabular}{lllll|}
1 & 2 & 3 & 4 & 5
\end{tabular} \\
\hline 2. Helped co-worker learn new skills or shared job knowledge. & \begin{tabular}{lllll|} 
& 2 & 3 & 4 & 5 \\
\end{tabular} \\
\hline 3. Helped new employees get oriented to the job. & $\begin{array}{|lllll|}1 & 2 & 3 & 4 & 5 \\
\end{array}$ \\
\hline 4. Used own vehicle, supplies or equipment for employer's business. & $\begin{array}{|lllll|}1 & 2 & 3 & 4 & 5 \\
\end{array}$ \\
\hline 5. Offered suggestions to improve how work is done. & \begin{tabular}{lllll|}
1 & 2 & 3 & 4 & 5 \\
\end{tabular} \\
\hline 6. Offered suggestions for improving the work environment. & $\begin{array}{|lllll|}1 & 2 & 3 & 4 & 5 \\
\end{array}$ \\
\hline 7. Came in early or stayed late without pay to complete a project or task. & \begin{tabular}{lllll|}
1 & 2 & 3 & 4 & 5 \\
\end{tabular} \\
\hline 8. Volunteered for extra work assignments. & \begin{tabular}{lllll|}
1 & 2 & 3 & 4 & 5 \\
\end{tabular} \\
\hline 9. Tried to recruit a person to work for your employer & \begin{tabular}{lllll|}
1 & 2 & 3 & 4 & 5 \\
\end{tabular} \\
\hline 10. Worked weekends or other days off to complete a project or task. & \begin{tabular}{lllll|} 
& 2 & 3 & 4 & 5 \\
\end{tabular} \\
\hline 11. Brought work home to prepare for next day. & \begin{tabular}{lllll|} 
& 2 & 3 & 4 & 5 \\
\end{tabular} \\
\hline 12. Volunteered to attend meetings or work on committees on own time. & $\begin{array}{lllll} & 2 & 3 & 4 & 5 \\
\end{array}$ \\
\hline 13. Said good things about your employer in front of others. & $\begin{array}{lllll}1 & 2 & 3 & 4 & 5\end{array}$ \\
\hline 14. Gave up meal and other breaks to complete work. & $\begin{array}{lllll}1 & 2 & 3 & 4 & 5\end{array}$ \\
\hline 15. Volunteered to work at after-hours or out-of-town events. & \begin{tabular}{lllll|} 
& 2 & 3 & 4 & 5 \\
\end{tabular} \\
\hline $\begin{array}{l}\text { 16. Helped co-worker with personal matter such as moving, childcare, car problems, } \\
\text { etc. }\end{array}$ & $\begin{array}{lllll}1 & 2 & 3 & 4 & 5\end{array}$ \\
\hline 17. Picked up or dropped off co-worker at airport, hotel, etc. & \begin{tabular}{lllll|}
1 & 2 & 3 & 4 & 5 \\
\end{tabular} \\
\hline 18. Covered a co-worker's mistake. & $\begin{array}{lllll} & 2 & 3 & 4 & 5 \\
\end{array}$ \\
\hline 19. Lent a compassionate ear when s & \begin{tabular}{lllll|}
1 & 2 & 3 & 4 & 5 \\
\end{tabular} \\
\hline
\end{tabular}




\begin{tabular}{|l|lllll|}
\hline $\begin{array}{l}\text { 20. Bought Girl Scout cookies or other fund raising items from a co-worker (or their } \\
\text { child). }\end{array}$ & 1 & 2 & 3 & 4 & 5 \\
\hline 21. Lent a compassionate ear when someone had a personal problem. & 1 & 2 & 3 & 4 & 5 \\
\hline 22. Lent money to a co-worker. & 1 & 2 & 3 & 4 & 5 \\
\hline 23. Lent car or other personal property to co-worker. & 1 & 2 & 3 & 4 & 5 \\
\hline $\begin{array}{l}\text { 24. Changed vacation schedule, work days, or shifts to accommodate co-worker's } \\
\text { needs. }\end{array}$ & 1 & 2 & 3 & 4 & 5 \\
\hline 25. Helped a less capable co-worker lift a heavy box or other object. & 1 & & & & \\
\hline 26. Brought candy, doughnuts, snacks, or drinks for co-workers. & 1 & 2 & 4 & 4 \\
\hline 27. Gave a written or verbal recommendation for a co-worker. & 1 & 2 & 3 & 4 & 5 \\
\hline 28. Went out of the way to give co-worker encouragement or express appreciation. & 1 & 2 & 3 & 4 & 5 \\
\hline $\begin{array}{l}\text { 29. Defended a co-worker who was being "put-down" or spoken ill of by other co- } \\
\text { workers or supervisor. }\end{array}$ & 1 & 2 & 3 & 4 & 5 \\
\hline
\end{tabular}

\section{Section Five}

1. What is your gender?

- male

- female

2. What is your ethnicity?

- White (non-Hispanic)

- Black (non-Hispanic)

- Hispanic

- Asian/Pacific Islander

- Native American/ Alaskan Native

- Middle Eastern

- Other

3. What is your age (in years)?

4. How many hours per week do you work?

- Less than 20 hours

- Between 20 and 40 hours

- 40 hours or more

- I am not employed

5. How long have you been employed at your current job (in years)?

6. What industry do you work in?

- Manufacturing

- Transportation

- Retail/Sales

- Services

- Public Administration/Government 
- Health Care

- Financial/ Real Estate

- Education

- Other

Thank you for completing part one of the study. For part two, you will need to ask one of your current coworkers to complete a brief online survey.

Please enter a code word below so that we are able to link your responses to those of your coworker. You will then give this code word to your coworker to enter before beginning their portion of the survey. Be sure they know they must use this code word in order to be able to access the survey.

Please enter your code word here:

If you feel comfortable, please provide us additional information about the coworker you have selected to participate in part two. (optional)

1. What is your coworker's name (first \& last):

2. What is their work phone number:

Please use the format $(\mathrm{xxx}) \mathrm{xxx}-\mathrm{xxxx}$

3. What is their email address:

Now, please take a moment to ask your coworker (email suggested) to logon and complete the second survey. Remember to provide them with:

1) Survey address: http://www.surveymonkey.com/s/coworkersurvey

2) Code word you entered in the previous page

\section{Section Six}

The study you just participated in was designed to investigate the effects of work engagement on the relationship between personality traits and work experiences, specifically organizational citizenship behaviors. It is important that we examine this relationship in a research setting in order enhance our understanding of employee-work dynamics in the applied setting.

If you have any questions or concerns about the study, please contact Alejandra Matamala at amata005@fiu.edu or Dr.Victoria Pace at vpace@fiu.edu.

Thank you very much for your participation. 
Appendix E

Coworker Survey

Exploring Personality Traits and Work Experiences: IRB \# 101410-01

You are being asked to participate in a research study for your coworker. The investigator of this study is Alejandra Matamala and she is a graduate student at FIU. The study will include about 400 students who are employed at least half-time and a coworker for each participant. Your participation will require about 15 minutes of your time. The goal of this study is to explore the relationships among personality traits and general behavior within work contexts.

If you decide to be a part of the study you will be asked to complete an online survey. You will be provided instructions on how to complete the survey online. Please read instructions carefully and follow them closely. You will be asked to answer general questions about your coworker's behavior in the work context.

The online survey will be similar to using a computer for work or play. We do not expect any harm to you by being in the study. Your survey will be identified by a random number not your name. All of your answers are private and will not be shared with anyone unless required by law. There is no cost or payment to you as a subject. However, your coworker will receive psychology course credit if you both choose to participate. You may ask questions about the study at any time. If you choose not to participate no one will be upset with you. You may skip any questions that you do not want to answer. You may also choose to stop your participation before your finish the survey.

Your honest answers will help researchers and employers understand how personality relates to job attitudes and experiences. Your data will be compared to data of other subjects. We will present the research results about the group of participants only, without any identification of individual participants or their specific data.

If you would like more information about this research after you are done, you can contact me via email at amata005@fiu.edu or Dr. Victoria Pace via email at vpace@fiu.edu. If you feel that you were mistreated or would like to talk with someone about your rights as a volunteer in this research study you may contact Dr. Patricia Price, the Chairperson of the FIU Institutional Review Board at 305-348-2618 or 305-348-2494.

If you would like to participate, please select "Yes, I agree to participate" and continue to the next page to complete the survey. If you would not like to participate, please select "No, I do not agree to participate" and close the browser window.

\section{Please select one:}

C Yes, I agree to participate $\quad \mathbf{C}_{\text {No, I do not agree to participate }}$ 
Thank you for helping your coworker participate in this study. In order to proceed, please enter the code word given to you by your coworker so that we are able to link the responses.

Please enter your code word here:

\section{Section One}

\begin{tabular}{|c|c|}
\hline $\begin{array}{l}\text { How often has your coworker done each of the following things on their present } \\
\text { job? }\end{array}$ & 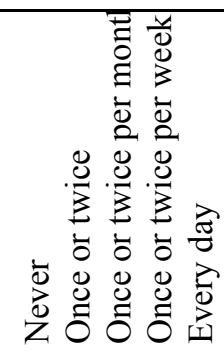 \\
\hline $\begin{array}{l}\text { 1. Drove, escorted, or entertained company guests, clients, or out-of-town } \\
\text { employees. }\end{array}$ & $\begin{array}{lllll}1 & 2 & 3 & 4 & 5\end{array}$ \\
\hline 2. Helped co-worker learn new skills or shared job knowledge. & $\begin{array}{lllll}1 & 2 & 3 & 4 & 5 \\
\end{array}$ \\
\hline 3. Helped new employees get oriented to the job. & $\begin{array}{lllll}1 & 2 & 3 & 4 & 5 \\
\end{array}$ \\
\hline 4. Used own vehicle, supplies or equipment for employer's business. & \begin{tabular}{lllll|}
1 & 2 & 3 & 4 & 5 \\
\end{tabular} \\
\hline 5. Offered suggestions to improve how work is done. & $\begin{array}{lllll}1 & 2 & 3 & 4 & 5 \\
\end{array}$ \\
\hline 6. Offered suggestions for improving the work environment. & $\begin{array}{lllll}1 & 2 & 3 & 4 & 5 \\
\end{array}$ \\
\hline 7. Came in early or stayed late without pay to complete a project or task. & $\begin{array}{lllll}1 & 2 & 3 & 4 & 5 \\
\end{array}$ \\
\hline 8. Volunteered for extra work assignments. & $\begin{array}{lllll}1 & 2 & 3 & 4 & 5 \\
\end{array}$ \\
\hline 9. Tried to recruit a person to work for your employer & $\begin{array}{lllll}1 & 2 & 3 & 4 & 5 \\
\end{array}$ \\
\hline 10. Worked weekends or other days off to complete a proje & $\begin{array}{lllll}1 & 2 & 3 & 4 & 5 \\
\end{array}$ \\
\hline 11. Brought work home to prepare for next day. & $\begin{array}{lllll}1 & 2 & 3 & 4 & 5 \\
\end{array}$ \\
\hline ork on committees on own time. & $\begin{array}{lllll}1 & 2 & 3 & 4 & 5 \\
\end{array}$ \\
\hline 13. Said good things about your employer in front of others. & $\begin{array}{lllll}1 & 2 & 3 & 4 & 5 \\
\end{array}$ \\
\hline 14. Gave & $\begin{array}{lllll}1 & 2 & 3 & 4 & 5 \\
\end{array}$ \\
\hline 15. Volunteered to work at after-hours or out-of-town $\mathrm{e}$ & $\begin{array}{lllll}1 & 2 & 3 & 4 & 5 \\
\end{array}$ \\
\hline $\begin{array}{l}\text { 16. Helped co-worker with personal matter such as moving, childcare, car problems, } \\
\text { etc. }\end{array}$ & $1 \quad 2 \quad 3 \quad 4 \quad 5$ \\
\hline 17. Picked up or dropped off co-worker at airport, hotel, etc. & $\begin{array}{lllll}1 & 2 & 3 & 4 & 5 \\
\end{array}$ \\
\hline 18. Cover & $\begin{array}{lllll}1 & 2 & 3 & 4 & 5 \\
\end{array}$ \\
\hline 19. Lent a compassionate ear when so & $\begin{array}{lllll}1 & 2 & 3 & 4 & 5 \\
\end{array}$ \\
\hline $\begin{array}{l}\text { 20. Bought Girl Scout cookies or other fund raising items from a co-worker (or their } \\
\text { child). }\end{array}$ & $\begin{array}{lllll}1 & 2 & 3 & 4 & 5\end{array}$ \\
\hline 21. Lent a compassionate ear when someone had a personal problem. & $\begin{array}{lllll}1 & 2 & 3 & 4 & 5 \\
\end{array}$ \\
\hline 22. Lent money to a co-worker. & $\begin{array}{lllll}1 & 2 & 3 & 4 & 5\end{array}$ \\
\hline 23. Lent car or other personal property to co-worker. & $\begin{array}{lllll}1 & 2 & 3 & 4 & 5 \\
\end{array}$ \\
\hline $\begin{array}{l}\text { 24. Changed vacation schedule, work days, or shifts to accommodate co-worker's } \\
\text { needs. }\end{array}$ & $123 \quad 3 \quad 4 \quad 5$ \\
\hline 25. Helped a less capable co-worker lift a heavy box or other object. & $\begin{array}{lllll}1 & 2 & 3 & 4 & 5\end{array}$ \\
\hline 26. Brought candy, doughnuts, snacks, or drinks for co-workers. & $\begin{array}{lllll}1 & 2 & 3 & 4 & 5 \\
\end{array}$ \\
\hline 27. Gave a written or verbal recommendation for a co-worker. & $\begin{array}{lllll}1 & 2 & 3 & 4 & 5 \\
\end{array}$ \\
\hline 28. Went out of the way to give co-worker encouragement or express appreciation. & $\begin{array}{lllll}1 & 2 & 3 & 4 & 5 \\
\end{array}$ \\
\hline $\begin{array}{l}\text { 29. Defended a co-worker who was being "put-down" or spoken ill of by other co- } \\
\text { workers or supervisor. }\end{array}$ & $\begin{array}{lllll}1 & 2 & 3 & 4 & 5\end{array}$ \\
\hline
\end{tabular}




\section{Section Two}

The study you just participated in was designed to investigate the effects of work engagement on the relationship between personality traits and work experiences, specifically organizational citizenship behaviors. It is important that we examine this relationship in a research setting in order enhance our understanding of employee-work dynamics in the applied setting.

If you have any questions or concerns about the study, please contact Alejandra Matamala at amata005@fiu.edu or Dr. Victoria Pace at vpace@fiu.edu.

Thank you very much for your participation. 